\title{
Assimilation for skin SST in the \\ NASA GEOS atmospheric data assimilation system
}

\author{
Santha Akella ${ }^{\mathrm{a}, \mathrm{b} *}$, Ricardo Todling ${ }^{\mathrm{a}}$ and Max Suarez ${ }^{\mathrm{a}, \mathrm{c}}$ \\ ${ }^{\mathrm{a}}$ Global Modeling and Assimilation Office, NASA GSFC, Greenbelt, MD \\ ${ }^{\mathrm{b}}$ Science Systems and Applications, Inc., Lanham, MD \\ ${ }^{\mathrm{c}}$ Universities Space Research Association, GESTAR, Columbia, MD
}

${ }^{*}$ Correspondence to: Code 610.1, NASA Goddard Space Flight Center, Greenbelt, MD 20771. E-mail: santha.akella@nasa.gov

The present article describes the sea surface temperature (SST) developments implemented in the Goddard Earth Observing System, Version 5 (GEOS-5) Atmospheric Data Assimilation System (ADAS). These are enhancements that contribute to the development of an atmosphere-ocean coupled data assimilation system using GEOS. In the current quasi-operational GEOS-ADAS, the SST is a boundary condition prescribed based on the OSTIA product, therefore SST and skin SST (Ts) are identical.

This work modifies the GEOS-ADAS Ts by modeling and assimilating near sea surface sensitive satellite infrared (IR) observations. The atmosphere-ocean interface layer of the GEOS atmospheric general circulation model (AGCM) is updated to include near surface diurnal warming and cool-skin effects. The GEOS analysis system is also updated to directly assimilate SST-relevant Advanced Very High Resolution Radiometer (AVHRR) radiance observations.

Data assimilation experiments designed to evaluate the Ts modification in GEOS-ADAS show improvements in the assimilation of radiance observations that extends beyond the thermal IR bands of AVHRR. In particular, many channels of hyperspectral sensors, such as those of the Atmospheric Infrared Sounder (AIRS), and Infrared Atmospheric Sounding Interferometer (IASI) are also better assimilated. We also obtained improved fit to withheld, in-situ buoy measurement of near-surface SST. Evaluation of forecast skill scores show marginal to neutral benefit from the modified Ts.

Key Words: SST; Diurnal Warming; AVHRR; Coupled Data Assimilation; NWP

Received...

This article has been accepted for publication and undergone full peer review but has not been through the copyediting, typesetting, pagination and proofreading process, which may lead to differences between this version and the Version of Record. Please cite this article as doi: 10.1002/qj.2988

This article is protected by copyright. All rights reserved. 


\section{Introduction}

Skin sea surface temperature (SST) is essential for atmospheric data assimilation system (ADAS) because it is used to specify the lower boundary condition over the oceans. The analysis needs it for direct assimilation of satellite radiance observations, and the atmospheric general circulation model (AGCM) uses it to calculate important variables such as air temperature and air-sea fluxes.

The Skin SST in the Goddard Earth Observing System (GEOS) ADAS (Rienecker et al. 2011; Bosilovich et al. 2015) is specified based on already existing daily SST data products (Reynolds et al. 2002, 2007; Donlon et al. 2012). However, the near surface temperature is complex and highly variable within the day (Saunders 1967; Soloviev and Lukas 1997; Fairall et al. 1996; Webster et al. 1996; Ward 2006; Gentemann and Minnett 2008). Daytime solar heating in calm wind conditions leads to the formation of a diurnal warm layer and close to the air-sea interface there is typically a cool skin layer (see Gentemann d Minnett (2008) and references therein). Radiometric (infrared and microwave) measurements and in-situ buoys close to the sea 1 surfa

surface have the capability to observe these changes (Donlon et al. 2002, 2007)

Prognostic models to simulate daily variation in skin SST have been implemented in the European Center for MediumRange Weather Forecasts (ECMWF)-AGCM by Beljaars (1997); Zeng and Beljaars (2005); Takaya et al. (2010a). The Zeng and Beljaars (2005) model has been used by Brunke et al. (2008) in the Community Atmosphere Model version 3.1 (CAM3.1). Results from these models indicate that they can realistically simulate the near surface observed temperature variations (Takaya et al. 2010a), and also impact the model mean climatologies of precipitation, outgoing longwave radiation (OLR), latent and sensible heat fluxes (Brunke et al. 2008). In addition to these prognostic models, several diagnostic models (Fairall et al. 1996; Gentemann et al. 2009; Kawai and Wada 2007), and statistical models (Gentemann et al. 2003; Filipiak et al. 2010) have also been proposed. Bellenger and Duvel (2009) provide a discussion of the main differences between prognostic (e.g., Zeng and Beljaars (2005)) and diagnostic (Fairall et al. 1996) models.
In the context of data assimilation (DA) While and Martin (2013) tested a prototype system for producing near real time global analysis of diurnal SST using the Takaya et al. (2010a) (hereafter TBBJ10) model. They sampled a TBBJ10 model generated trajectory to obtain synthetic observations of a diurnally varying skin SST. Those observations were then assimilated using the same model in an attempt to recover the true initial state of the model, net heat flux and wind speed at every time step. Their experiments showed that they could improve the fit to the true state (compared to first guess) and also recover the initial model state and heat fluxes, but not the wind speed. One of their conclusions was that accurate specification of errors in forcing fields (heat fluxes and winds) and observations (of SST) are very important for a diurnal analysis of the global SST field. McLay et al. (2012) also implemented a version of the TBBJ10 model, without a cool skin layer in the Navy Operational Global Atmospheric Prediction System (NOGAPS). They obtained an improvement in precipitation (midday peak value and daily accumulation), and statistically significant differences in latent, sensible heat fluxes, OLR, $2 \mathrm{~m}$ air temperature, etc. Overall, the diurnal skin SST provided improved forecasts in the tropics, with lower impact in mid-latitudes.

The objective of this article is to directly estimate skin SST using satellite radiance observations and the prognostic diurnal warming model of TBBJ10 and diagnostic cool skin layer model of Fairall et al. (1996) (now onwards F96) in the context of the NASA- GEOS version-5 ADAS (Rienecker et al. 2008; Bosilovich et al. 2015). Accurate interfacial states such as the skin SST (Curry et al. 2004) play an important role in a atmosphereocean coupled data assimilation (CDA) system (Dee et al. 2014; Lea et al. 2015; Laloyaux et al. 2016a,b); see Brassington et al. (2015) for a recent summary of the development of CDA systems at various operational centers. This article documents some of the preliminary steps that have been taken in the ADAS of the NASA Global Modeling and Assimilation Office (GMAO) to enhance the coupling between the atmosphere and ocean DA systems in preparation for an integrated earth system analysis (IESA).

The SST and sea ice concentration in the quasi-operational GEOS-5 ADAS come from the Operational Sea Surface Temperature and Ice Analysis system (OSTIA, Donlon et al. 
(2012)) as lower boundary conditions. We made the following changes to the treatment of the SST in the ADAS. Since the OSTIA SST is an estimate of foundation SST, it does not contain diurnal variability, therefore we incorporated the TBBJ10 and F96 models into the AGCM to generate additional background (or, first guess) fields that are relevant to the diurnal variation of skin SST besides the already available upper air fields required to perform an atmospheric analysis. The atmospheric analysis is carried out using the Gridpoint Statistical Interpolation (GSI) (Kleist et al. 2009a,b) and it has been modified to analyze skin SST along with its upper air analysis. Taking advantage of the extensive use of the Advanced Very High Resolution Radiometer (AVHRR) measurements for SST retrievals (Reynolds et al. 2007; May et al. 1998), we included AVHRR brightness temperature observations from both NOAA-18 and Metop-A satellites to the ADAS observing system. All satellite observations are directly assimilated by GSI using the community radiative transfer model $\left(\right.$ CRTM $\left.^{*}\right)$ (Han et al. 2006; Chen et al. 2010); the interface between the GSI and CRTM has also been modified to account for e skin SST. We emphasize that with these changes in place, the CRTM uses a diurnally varying skin SST to simulate brightness temperatures (for all satellite sensors/channels), as opposed to using the daily OSTIA SST field. Finally, the analysis increment (includes the increment in skin SST) is then used to force the AGCM through the incremental analysis update (IAU) approach (Bloom et al. 1996).

P L Layout of this article is as following. Section 2 provides a description of the modifications to the GEOS-AGCM to obtain diurnally varying skin SST. We include some account of the urbidity of water due to biological activity, because it affects the net shortwave radiation that is absorbed within the nearsurface ocean; however, we parameterized the impact of Langmuir circulation. Section 3 details the interconnectivity of the AGCM and GSI analysis (observing system and CTRM) that is involved in calculating an estimate for skin SST. Section 4 presents the experimental set up. Section 5 shows results with and without the modified SST, including and excluding the AVHRR observations. Corresponding changes in the performance of the numerical weather prediction (NWP) system are presented in section 6 . Finally, in section 7 , we summarize our results, followed with a brief outline of current work.

\section{Skin SST model in the GEOS-AGCM}

In the GEOS-AGCM, net surface heat flux over the ocean served as a diagnostic variable (Molod et al. 2012) and the skin SST (denoted by $T_{s}$ ) is set equal to the daily OSTIA SST. This section describes changes made to this formulation to obtain a diurnally varying $T_{s}$. Following F96, we calculate the near sea surface temperature at any depth

$$
T(z)=T_{d}-\Delta T_{c}+\Delta T_{w}(z)
$$

where $T_{d}$ is the OSTIA SST, $\Delta T_{w}$ and $\Delta T_{c}$ denote diurnal warming and cool-skin temperature changes respectively, and are described below; $T_{s}$ is simply $T(z=0)$.

\subsection{Cool skin}

Up to a few millimeters below the air-sea interface, heat loss occurs due to the exchange of net longwave, sensible and latent fluxes. This negative heat flux dominates the absorbed shortwave radiation resulting in the formation of a cool skin layer (F96; Saunders (1967); Curry et al. (2004)). We follow F96 to diagnostically calculate the thickness and temperature drop, $\Delta T_{c}$, within this cool layer,

$$
\Delta T_{c}=\frac{\delta}{\rho_{w} c_{w} k_{w}} Q_{n e t}^{c}
$$

where $\rho_{w} c_{w}$ and $k_{w}$ denote density, heat capacity and thermal conductivity of sea water respectively. $\delta$ is the thickness of this layer,

$$
\delta=\frac{\lambda \nu_{w}}{u_{*, w}}
$$

$\nu_{w}$ is the kinematic viscosity, friction velocity over water is given by $u_{*, w}=u_{*, a} \sqrt{\rho_{a} / \rho_{w}} ; u_{*, a}$ is the atmosphere friction velocity and $\rho_{a}$ is air density. The net heat flux in this cool layer, $Q_{n e t}^{c}$, is give by

$$
Q_{n e t}^{c}=\left(H_{s}+H_{l}-L W_{n e t}\right)-f_{c} S W_{n e t}^{s}
$$


where $H_{s}, H_{l}, L W_{n e t}$, and $S W_{n e t}^{s}$ denote the surface sensible, latent, net longwave and shortwave heat fluxes respectively; as in F96 heat fluxes are positive downward. Only a fraction $\left(f_{c}\right)$ of $S W_{n e t}^{s}$ is absorbed in the cool-skin layer; $f_{c}$ and $\lambda$ are calculated as in F96. Also following F96, we assume a linear variation of temperature within this layer, $T(z)=T_{\delta}-\Delta T_{c}\left(1-\frac{z}{\delta}\right), 0 \leq$ $z \leq \delta . T_{\delta}$ is the temperature at depth $z=\delta$, i.e., at the top (bottom) of the warm (cool) layer, is explained below.

\section{Diurnal warming}

Following the single column prognostic model of TBBJ10, we calculate the diurnal warming as

$\frac{\partial\left(T_{\delta}-T_{d}\right)}{\partial t}=\frac{\left(\mu_{s}+1\right) Q_{n e t}^{w}}{\mu_{s} \rho_{w} c_{w} d}-\frac{\left(\mu_{s}+1\right) \kappa u_{*, w} f(L a)}{d \phi_{h}(\zeta)}\left(T_{\delta}-T_{d}\right)$,

where $d$ denotes a fixed depth below the cool layer and $\kappa=$ 0.4 is the von Kármán constant; $L a=\sqrt{\frac{u_{*, w}}{u_{s}}}$, is the Langmuir number, $u_{s}$ is the surface Stokes velocity, and $f(L a)=L a^{-2 / 3}$. The stability parameter, $\zeta=z / L$ involves the Obukhov length, is given by $L=\frac{\rho_{w} c_{w} u_{*, w}^{3}}{\kappa g \alpha_{w} Q_{n e t}^{w}}$. The similarity function is defined as 1

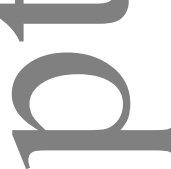

$$
\phi_{h}(\zeta)=\left\{\begin{array}{cc}
1+\frac{5 \zeta+4 \zeta^{2}}{1+3 \zeta+0.25 \zeta^{2}} & \text { if } \zeta \geq 0 \\
(1-16 \zeta)^{-1 / 2} & \text { if } \zeta<0
\end{array}\right.
$$

where $\mu_{s}$ is an empirical parameter $(\leq 1)$ whose small values lead to sharper near-surface peaking of the temperature profile within he warm layer $(\delta \leq z \leq d)$ : $T(z)=T_{\delta}-\left(\frac{z-\delta}{d-\delta}\right)^{\mu_{s}}\left(T_{\delta}-T_{d}\right)$, $\Delta T_{w}(z)=T(z)-T_{d}$.

Our implementation of the TBBJ10 model differs in the following fashion. Due to the absence of a wave model in the GEOS, we set the surface Stokes velocity $u_{s}=1 \mathrm{~cm} / \mathrm{s}$ globally. This value was obtained based on trial and error and off-line matching of model simulations with buoy-measured temperature time series. For this reason, we do not adjust the second term on the right hand side of (5) as done by TBBJ10 and Zeng and Beljaars (2005) (hereafter ZB05) to obtain a slow decay of $\Delta T_{w}$ after sunset (when $S W_{n e t}^{s} \approx 0$ ). In the future, we plan to revisit these choices in coordination with the implementation of a wave model to simulate the relaxation of $T_{\delta}$ to $T_{d}$.
The net heat flux in the warm layer, $Q_{n e t}^{w}$, is given by

$$
Q_{n e t}^{w}=S W_{n e t}^{w}+\left(L W_{n e t}-H_{s}-H_{l}\right)
$$

where $S W_{n e t}^{w}=S W_{n e t}^{s}-S W_{P E N}$, is the net shortwave radiation absorbed in the warm layer. ZB05 and TBBJ10 used the three-band absorption profile of Soloviev (1982) to obtain the penetrating shortwave radiation, $S W_{P E N}$ given by

$$
\frac{S W_{P E N}(z)}{S W_{n e t}^{s}}=\sum_{i=1}^{N=3} a_{i} \exp \left(-z b_{i}\right)
$$

where $z=d$; the coefficients $a_{i}$ and $b_{i}$ are as in ZB05. A modified version of the nine-band model of Paulson and Simpson (1981) was used by Gentemann et al. (2009) and While and Martin (2013). Besides the obvious differences in the number of terms $(N=3$ or 9$)$ and values of coefficients $\left(a_{i}, b_{i}\right)$, the nineband model differs from the three-banded model because it also includes contribution from the solar zenith angle in $b_{i}$ (Gentemann et al. 2009).

Ohlmann and Siegel (2000) and Wick et al. (2005) suggested that $S W_{P E N}$ is sensitive to the upper-ocean chlorophyll concentration, solar zenith angle and cloud cover. Ohlmann (2003) suggested a chlorophyll dependent, parameterized shortwave absorption model based on results from an ocean radiative transfer model which considered absorption in $250-2500 \mathrm{~nm}$ wavelength range. In the present work, we make an effort to compare the impact of three-band (Soloviev 1982) and nine-band (Gentemann et al. 2009) shortwave absorption models in our implementation of TBBJ10 diurnal warming by simply changing the way we calculate $S W_{P E N}$. We also tried to include the impact of chlorophyll, but unlike Ohlmann (2003) we consider absorption in the visible and ultraviolet (UV) wavelength range in a simple fashion,

$$
\begin{aligned}
S W_{P E N}(z)= & {\left[\left(1-\alpha_{V R}\right) D R_{U V}+\left(1-\alpha_{V F}\right) D F_{U V}\right] \beta_{U V}+} \\
& {\left[\left(1-\alpha_{V R}\right) D R_{P A R}+\left(1-\alpha_{V F}\right) D F_{P A R}\right] \beta_{P A R} }
\end{aligned}
$$

where $\beta_{U V}=\exp \left(-z K_{U V}\right)$ and $\beta_{P A R}=\exp \left(-z K_{P A R}\right)$, $\alpha_{V R}$ and $\alpha_{V F}$ denote surface direct beam and diffuse albedos over water, respectively. The surface downwelling direct and 
diffuse fluxes in the $\mathrm{UV}$ are given by $D R_{U V}$ and $D F_{U V}$ respectively. $D R_{P A R}$ and $D F_{P A R}$ denote the direct and diffuse photosynthetically active radiation (PAR) fluxes, respectively (for details regarding these fluxes in the GEOS-AGCM, please see Rienecker et al. (2008)). The extinction coefficient $K_{U V}$ is set to a constant value of $0.09 \mathrm{~m}^{-1}$, whereas $K_{P A R}$ is specified based on a climatology of chlorophyll concentration derived from SeaWiFs and is the same as that used in the GEOS atmosphereocean coupled model (Vernieres et al. 2012; Ham et al. 2014),

see Figure 1. Typically higher concentrations of chlorophyll are found near coastlines and in regions where upwelling of cold wăter takes place. Turbidity of water is higher in these regions, leading to larger $K_{P A R}$, consequently shortwave radiation does not penetrate deep into the water column (for details, please see Morel et al. (2007)). Based on (9) high values of $K_{P A R}$ imply lower $\beta_{P A R}$ and $S W_{P E N}$, hence larger $S W_{n e t}^{w}$, i.e., more shortwave radiation in the warm layer. This inverse relationship between $K_{P A R}$ and $S W_{n e t}^{w}$ can be also noticed at locations with less chlorophyll concentrations, which have lower values of $K_{P A R}$, therefore, sunlight penetrates into deeper ocean.

In the skin SST model we set depth $d=2 \mathrm{~m}$, and followed the procedure described by ZB05 for the parameter $\mu_{s}$ and set it to 0.2. As in ZB05 and TBBJ10, we integrate (5) in time, using an implicit scheme to predict $T_{\delta}$, and then use (2) and (1) to calculate $T(z)$.

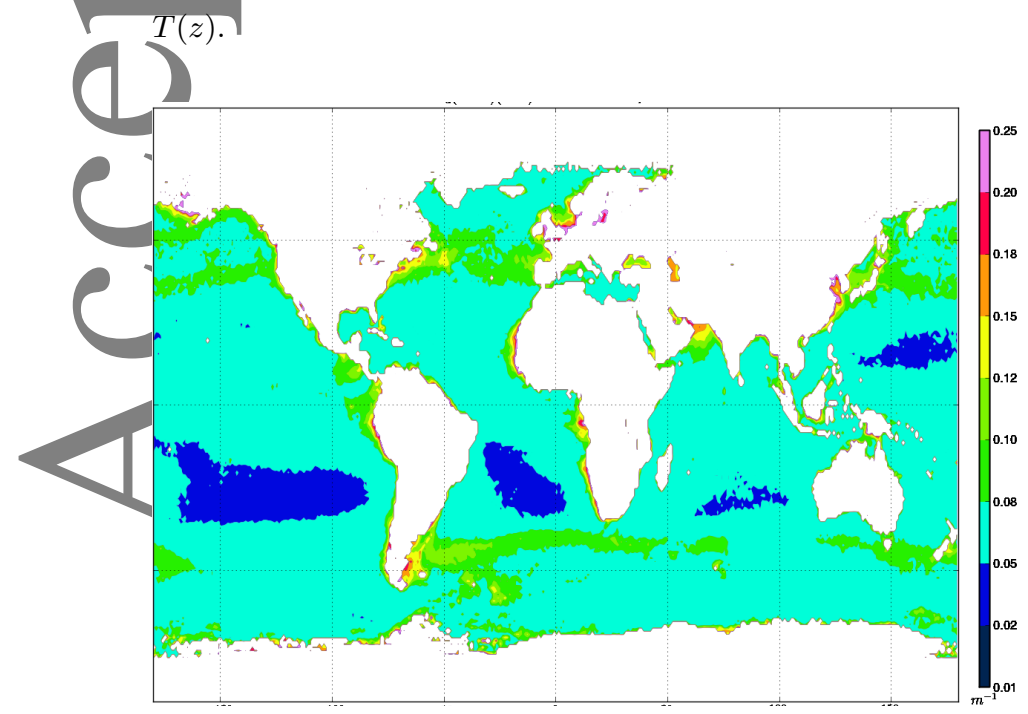

Figure 1. Climatological downward diffuse attenuation coefficient for the photosynthetically available radiation, $K_{P A R}\left(m^{-1}\right)$ for the month of April. Values over land and sea ice have been masked and are not used in open ocean computations.

Atmospheric processes induce a two-way feedback between aerosols (particularly, dust) and skin SST (May et al. 1992;
Merchant et al. 2006). Here we make no attempt to diagnose those mechanisms; for now, we leave this topic to future work. We use the Goddard chemistry, aerosol, radiation, and transport (GOCART) model, active in GEOS-AGCM (Rienecker et al. 2008), and therefore aerosols impact the skin SST simulated in the model.

\section{Analysis of skin SST using GEOS-ADAS}

Using the first guess, or background fields generated by the GEOS-AGCM, we analyze a wide variety of satellite and in situ observations in the framework of GEOS-ADAS (Rienecker et al. 2008, 2011). The atmospheric analysis uses the three-dimensional variational (3D-Var), first-guess-at-the-appropriate-time (FGAT) flavor of GSI (Kleist et al. 2009a,b). GSI analysis control vector includes $T_{s}$, surface pressure and also their upper air fields. The analysis increment: $T_{s}^{i n c}$ (difference between analyzed and background $\left.T_{s}\right) T_{s}^{a n a}-T_{s}^{b k g}$, was not taken into account by the ensuing AGCM integration (Derber and Wu 1998; Rienecker et al. 2008). To estimate $T_{s}$, following changes were made to the GEOS-ADAS.

\subsection{Observation minus background computation and}

\section{background error}

With the inclusion of the skin SST model in the AGCM (section 2) additional (two dimensional) fields (depths: $\delta$ and $d$, temperatures: $T_{\delta}$ and $T_{d}$ and the temperature drop due to the cool skin layer: $\Delta T_{c}$ ) are available to the GSI. FGAT for these additional fields at the observation time, $t_{k}$ and location (latitude, longitude and depth: $z_{o b}$ ) are obtained in the following steps, (i) temporally (linearly) interpolate above fields to $t_{k}$, (ii) spatially interpolate them to the observation spatial location using bilinear interpolation, and (iii) calculate the temperature at the observation depth following the temperature profile in the coolskin (section 2.1) and diurnal warm (section 2.2) layers according to,

$$
T\left(z_{o b}\right)=\left\{\begin{aligned}
T_{\delta}-\Delta T_{c}\left(1-\frac{z_{o b}}{\delta}\right) & \text { if } 0 \leq z_{o b} \leq \delta \text { (Cool Layer) } \\
T_{\delta}-\left(\frac{z_{o b}-\delta}{d-\delta}\right)^{\mu_{s}}\left(T_{\delta}-T_{d}\right) & \text { if } \delta<z_{o b} \leq d \text { (Warm Layer) }
\end{aligned}\right.
$$


This temperature profile $T\left(z_{o b}\right)$ is used as the first guess or background field to calculate observation minus background $(\mathrm{OMB})$

Observations that are taken close to the sea surface $\left(z_{o b} \approx 0\right)$ are influenced by diurnal warming and cool skin and $T\left(z_{o b}\right) \approx T_{s}$. Whereas observations taken below the cool layer $\left(z_{o b}>\delta\right)$ feel the presence of a warm layer only (Donlon et al. 2007).

For in situ measurements, $z_{o b}$ is the measurement depth; for the satellite observations, it is non-trivial and it is related to the wavelength of the electromagnetic radiation (Wieliczka et al. 989), and scan angle (C. Gentemann, personal communication, 2012). Following Donlon et al. (2007) we set the following values for $z_{o b}$

$$
z_{o b}=\left\{\begin{aligned}
15 \mu \mathrm{m} & \text { all infrared sensors } \\
1.25 \mathrm{~mm} & \text { all microwave sensors. }
\end{aligned}\right.
$$

A more precise (wavelength dependent) computation of the $z_{o b}$ for infrared (IR) and microwave (MW) sensors is beyond the scope of this study.

Computation of the OMB residuals for in situ observations is trivial. Whereas for satellite radiance observations, we first 1 calculate $T\left(z_{o b}\right)$ using (11) and (10). This temperature at $z_{o b}$ and upper-air atmospheric fields are then used by the CRTM to simulate a brightness temperature $\left(T_{b}\right)$ and hence obtain the OMB any satellite/sensor; the CRTM also returns the sensitivity $\partial T_{b} / \partial T_{z}$. However, since the analysis control variable is $T_{s}$, need the Jacobian of the brightness temperature with respect to $T_{s}: \partial T_{b} / \partial T_{s}$ for the linearized observation operator needed in the 3D-Var minimization. This is obtained through the chain rule, $\partial T_{b} / \partial T_{z}=\left(\partial T_{b} / \partial T_{s}\right)\left(\partial T_{s} / \partial T_{z}\right)$, where we use a simple approximation for the Jacobian, $\partial T_{s} / \partial T_{z}=1$. This is reasonable for IR observations because we assume in (11) that the penetration depth is $15 \mu \mathrm{m}$ (very close to the air-sea interface, $T(z=15 \mu \mathrm{m}) \approx$ $\left.T_{s}\right)$. But it is not accurate for MW observations, because $z_{o b} \sim$ $O(1 \mathrm{~mm})$. Since this approximation for $\partial T_{s} / \partial T_{z}$ is not realistic for MW observations, it will require further investigation in future work.

Regarding the background error for $T_{s}$, we use the same covariance structure as in Derber and Wu (1998) and follow their procedure in assuming it to be independent from other analysis control variables; the correlation length scales and standard deviation are shown in Figure 2. As noted in Derber and Wu (1998), the correlation length scales can be improved upon to account for the short correlation length scales that are typically seen for oceanic variables such as the SST (Donlon et al. 2012), this topic is part of our current work (section 7).
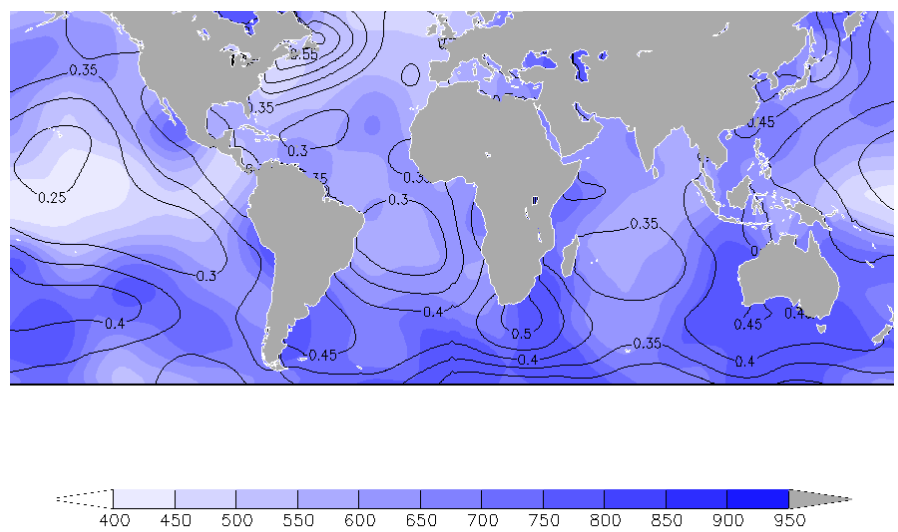

Figure 2. $T_{s}$ background error correlation length scales is shaded (in km) and standard deviation is contoured with $0.05^{\circ} \mathrm{C}$ interval between $\pm 60^{\circ}$ latitudes. Values of standard deviation range from zero over sea ice-covered regions to about $0.7^{\circ} \mathrm{C}$ in regions of high variability, such as the Gulf stream and Kuroshio current regions; correlation length scales vary between 400 and $900 \mathrm{~km}$; land has been masked out.

\section{2. $\quad$ SST relevant additional observations}

SST relevant observations are available from in situ platforms (ships, moored and drifting buoys). Though they directly measure temperature, they have limited spatial coverage and temporal frequency. Also, they do not measure within microns (or even millimeters) of the air-sea interface (Donlon et al. 2002). The measurements that are most representative of the skin SST are made by drifting buoys (Lumpkin and Pazos 2007). They record hourly temperature at approximately $20 \mathrm{~cm}$ depth, and therefore provide most temporally continuous observations of the SST, close to the air-sea interface. Unfortunately, there is no uniform global coverage, and there are significant gaps at high latitudes. Our immediate goal is to focus on the skin SST, so we focus on the assimilation of satellite observations, and withhold in situ SST observations to passively monitor the OMB to diagnose any systematic biases.

Satellite measurements in the IR $(3.7-12 \mu \mathrm{m}$ wavelengths) and MW (6 - 11GHz frequency) provide long term, continuous measurements of near-surface temperature (Hosoda 2010; Castro et al. 2008; Donlon et al. 2007). In GEOS-ADAS, analysis 
of MW observations in the SST relevant frequency range is currently under development, and we do not consider them in this work. AVHRR observations in the IR have been extensively used for SST retrievals (May et al. 1998; Reynolds et al. 2007). Taking advantage of their availability from the Environmental Modeling Center (EMC), we added AVHRR $T_{b}$ observations from both NOAA-18 and Metop-A satellites to the GEOSADAS observing system. Level 1B, global area coverage (GAC) ocean only data was obtained at a resolution of about $4 \mathrm{~km}^{2}$, it includes a cloud mask and it has information in three IR window channels (3B centered around $3.7 \mu \mathrm{m}$, channels 4 and 5 approximately around 11 and $12 \mu \mathrm{m}$ wavelengths respectively). Due to solar contamination (Liang et al. 2009) channel 3B (henceforth referred as channel 3) daytime data is not used. The procedure for reading, spatial thinning, observational scoring and quality control (QC) of the data follows the treatment for any IR sounding observations currently handled by GSI. Abundant precaution is taken to detect clouds and to reject observations that are deemed to be affected by them (Akella et al. 2016). Channel 3 is most sensitive to skin temperature, therefore it A has the most potential to drive the $T_{s}$ analysis increment. However, similar wavelength IR channels (on other sensors) are currently inactive (i.e., not assimilated) in the GEOS-ADAS and in general, it is challenging to assimilate such observations becausse of the complexities in radiative transfer modeling at such yavelengths (Chen et al. 2012). Nevertheless we have attempted to conservatively assimilate observations from this channel (as ready mentioned, only at local nighttime), and by having a smaller contribution to the 3D-Var cost function (and its gradient), achieved by down-weighting the observational error variance computed using the GSI QC procedure (Derber and Wu 1998; Akella et al. 2016). Approximately 36 thousand observations are available within a $6 \mathrm{hr}$ analysis window (in all 3 AVHRR channels, and on both NOAA-18 and Metop-A satellites) after thinning and scoring, of which about $65 \%$ observations are rejected by QC procedure.

Due to errors in the satellite instruments and their calibration, and also systematic errors in radiative transfer models, satellite radiance data assimilation involves usage of a variational bias correction (VarBC) procedure (Derber and Wu 1998; Dee and
Uppala 2009; Eyre 2016). As all other satellite observations, the AVHRR observations are also bias corrected using the VarBC. The observational error standard deviation, $\sigma_{o}$ is set to $0.60,0.68$, and $0.72^{\circ} \mathrm{K}$ for channels 3, 4 and 5 respectively. These values are chosen such that the AVHRR $\sigma_{o}$ is lower than that specified for other surface sensitive IR observations.

\subsection{Application of skin SST analysis increment}

Using all the observations (regularly analyzed by GEOS-ADAS, plus AVHRR) and background fields (section 3.1), we obtain analyzed fields ( $T_{s}$ included). All analysis increments are applied to the GEOS-AGCM using the IAU approach (Bloom et al. 1996). We apply the increments of upper-air and surface pressure fields over all surface types (ice, land, water), but the $T_{s}$ increment is applied only over open ocean (where the fraction of water is equal to 1$)$.

\section{Experimental setup}

The following additions to GEOS-ADAS:

(a) modeling of diurnal variations in SST in GEOS-AGCM,

(b) addition of AVHRR observations to the analysis system,

(c) usage of the analysis increment in skin SST by the AGCM, are evaluated with the aid of following experiments.

(i) CTL mimics the current quasi-operational configuration of GEOS-ADAS with a 3D-Var DA. It uses OSTIA SST for skin SST and AVHRR observations are not assimilated. The analysis increment in $T_{s}$ is ignored in the AGCM integrations.

(ii) AVH is like the CTL, but it adds AVHRR data from NOAA18 and Metop-A to the analysis system. Here the model continues to ignore the $T_{s}$ analysis increment.

(iii) tSkin is similar to the CTL and does not assimilate AVHRR data. But it has the skin SST model turned on. Therefore the model produced diurnal warming and cool skin are used to compute $T_{s}$, which is then used by the CRTM. The Skin SST model used the $K_{P A R}$ (9) for computation of the penetrating shortwave radiation. The $T_{s}$ analysis increment is ignored by the model. 
(iv) Assim_Kpar uses the skin SST model, configured as in tSkin. In addition it assimilates the AVHRR observations. The CRTM uses $T\left(z_{o b}\right)$ (given by (10)) with the values of $z_{o b}$ for all IR and MW instruments given in (11). Here the analysis increment in $T_{s}$ is used by the AGCM through IAU. This experiment, therefore, implements all items (a)(c) above.

v) Assim_Sol82 is like Assim_Kpar, but uses the three-band Soloviev (1982) shortwave absorption model instead of the $K_{P A R}$ based $S W_{P E N}$.

(vi) Assim_PS81 is like Assim_Kpar, but uses the modified version of Paulson and Simpson (1981) nine-band shortwave absorption model from Gentemann et al. (2009). $1+1$ A summary of the experimental setup is given in Table 1, we will refer to experiments: (iv)- (vi) as $T_{s}$ assimilation experiments.

Using initial conditions from the above ADAS experiments, we also performed NWP experiments (see section 6).

The experiments are configured at about $\frac{1}{2}^{\circ}(576 \times 361)$ horizontal resolution on a cube sphere (C180) grid (Putman and Lin 2007), with 72 vertical levels (Rienecker et al. 2008), and a time step of 450 seconds. All experiments are started with the same initial conditions, with 15-days (16- 31 March 2012) of spinup; all evaluations are for April 2012 ${ }^{\dagger}$.

\section{Results and discussion}

(Q).

start with a description of the results from the skin SST model, focussing on the cool skin and diurnal warming. Thereafter proceed to evaluate the analysis of observations via direct examination of observations minus background (OMB) and observation minus analysis (OMA), including in situ SST withheld observations (section 5.2). We compare the $T_{s}$ analysis increments in (section 5.3). As noted before, we do not apply the $T_{s}$ analysis increment $\left(T_{s}^{i n c}\right)$ over land and sea ice (section 3.3), thus we focus on the open ocean results.

\section{1. $\quad$ Skin SST}

The skin SST model is used in the tSkin and $T_{s}$ assimilation experiments. The April 2012 monthly mean temperature drop

\footnotetext{
${ }^{\dagger}$ AVHRR satellite bias correction coefficients (for both NOAA-18 and Metop-A) were spun up from zero values using low resolution experiments.
}

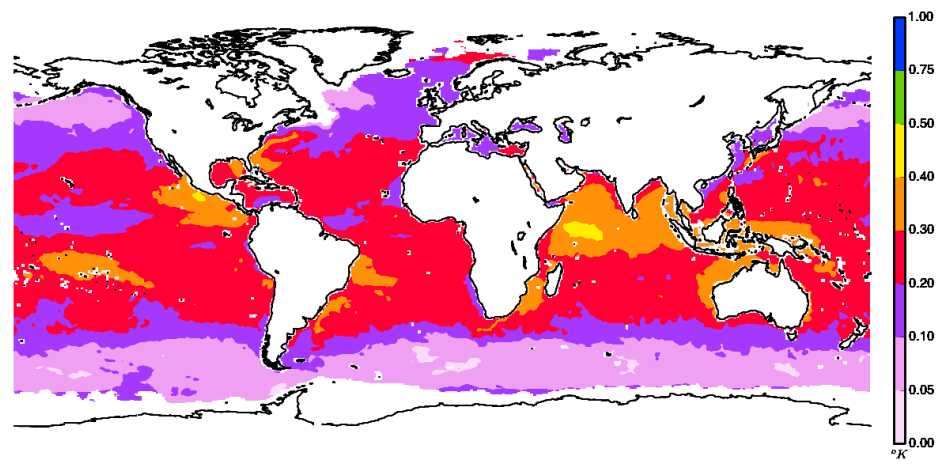

Figure 3. April 2012 monthly mean of the temperature drop $\Delta T_{c}\left({ }^{\circ} K\right)$ due to the cool-skin layer for the tSkin experiment. Land and sea ice have been masked.

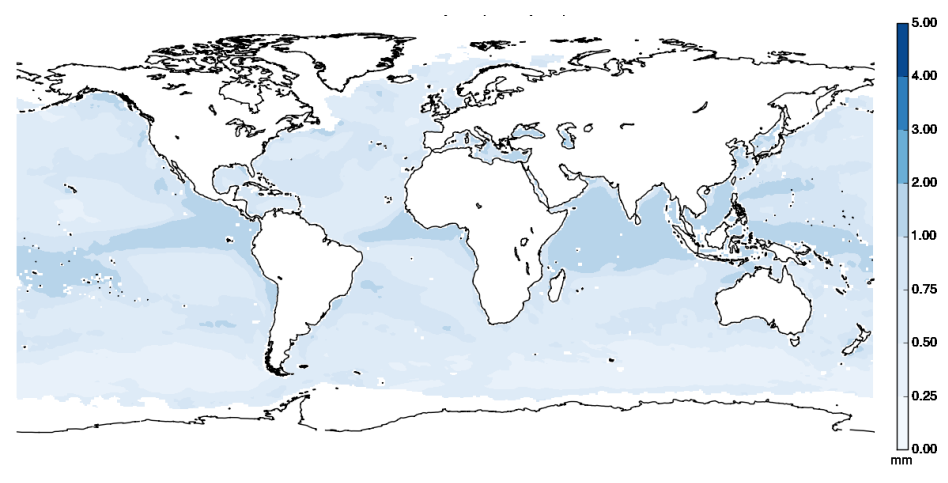

Figure 4. Same as in Fig. 3 but for the depth of the cool-skin layer $\delta(\mathrm{mm})$

$\left(\Delta T_{c}\right)$ due to the cool-skin layer, for tSkin experiment is shown in Fig. 3. $\Delta T_{c}$ peaks to about $0.4-0.5^{\circ} \mathrm{K}$ in light wind conditions (in tropics) and decreases to around $0.05^{\circ} \mathrm{K}$ with increasing wind speed (for instance in the Southern Ocean), similar results were also reported by Saunders (1967) and F96. The mean thickness of the cool layer $(\delta)$ is shown in Fig. 4, and it is inversely related to friction velocity over water ( $u_{*, w}$, not shown) via (3).

Based on (2), we also expect a direct correlation between $\Delta T_{C}$ and the net heat flux in the cool layer $\left(Q_{n e t}^{c}\right)$. During daytime we obtained a decrease of about $0.1^{\circ}-0.2^{\circ} \mathrm{K}$ in $\Delta T_{c}$, due to (4), which includes a negative contribution from the net surface shortwave radiation $\left(S W_{n e t}^{s}\right)$. Regions of low wind speed, for instance the tropical eastern Pacific and Indian Oceans, show largest daily variability, similar variation was noted by F96. We obtain similar values for cool skin layer fields $\left(\Delta T_{c}, \delta\right)$ in the $T_{s}$ assimilation experiments.

The combination of diurnal warming $\left(\Delta T_{w}\right)$ and cool skin impacts the $T_{s}(1)$; difference between $T_{s}$ and OSTIA SST $\left(T_{d}\right)$ 
Table 1. Summary of experimental setup (details are given in section 4)

\begin{tabular}{cccccc}
\hline Exp. Name & skin SST model & Shortwave penetration & $T_{s}$ used by CRTM & AVHRR obs & $T_{s}$ Analysis Increment \\
\hline CTL & off & N/A & OSTIA SST & not used & not used \\
AVH & off & N/A & OSTIA SST & analyzed & not used \\
tSkin & on & $K_{P A R}$ based & skin SST (Eq.(1)) & not used & not used \\
\hline Assim_Kpar & on & $K_{P A R}$ based & $T\left(z_{o b}\right)$ (Eq.(10)) & analyzed & used \\
Assim_Sol82 & on & Soloviev (1982) & $T\left(z_{o b}\right)$ (Eq. (10)) & analyzed & used \\
Assim_PS81 & on & modified Paulson and Simpson $(1981)$ & $T\left(z_{o b}\right)$ (Eq.(10)) & analyzed & used \\
\hline
\end{tabular}

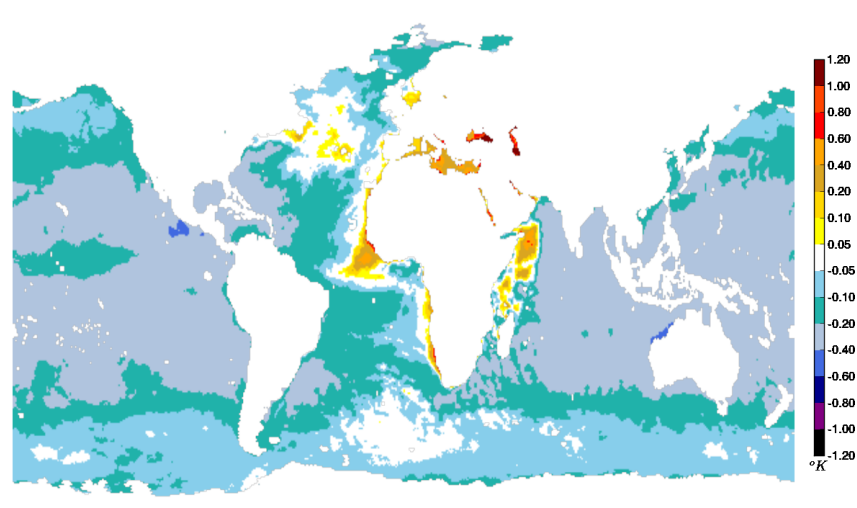

is shown in Fig. 7. Difference between Assim_Kpar and tSkin ${ }_{100}^{1.20}$ is small and noisy, as shown in Fig. 7(b). Assim_Sol82 and ${ }_{0.00}^{0.00}$ Assim_PS81 have about $20 \mathrm{~W} / \mathrm{m}^{2}$ more net surface shortwave ${ }_{0.10}^{0.20}$ radiation $\left(S W_{n e t}^{s}\right)$ than $\mathrm{tSkin}$, which is perhaps the largest contrib.os utor to the differences in $T_{s}$, in Fig. 6(c, d). This result highlights the importance of $S W_{P E N}$ in modeling diurnal warming

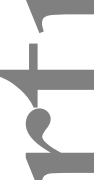

ras

Figure 5. April 2012 monthly mean difference between skin and OSTIA SSTs $\left({ }^{\circ} \mathrm{K}\right)$ for the tSkin experiment at $12 \mathrm{UTC}$.

The diurnal SST amplitude (DSA) metric has been used by TBBJ10 to compare their modifications to the ZB05 scheme; it has also been used by Bellenger and Duvel (2009) and McLay et al. (2012). At any given location, TBBJ10 defined DSA to be shown in Fig. 5 for the tSkin experiment. Positive (negative) differences are related to the increase (decrease) due to the contribution from $\Delta T_{w}\left(\Delta T_{c}\right)$. The diurnal warming is driven by nsolation and modulated by winds (5). Tropical oceans (with low wind speed) have largest diurnal warming (as also reported by ZB05 and TBBJ10), for example, in the Indian Ocean (Somali basin in Fig. 5) we obtain $\Delta T_{w}$ around $2^{o} K$. In the extratropics we obtain smaller diurnal warming than in the tropics due to the typical higher wind speeds and lesser insolation.

Figure 6 shows the difference in skin SST for the $T_{s}$ assimilatign experiments from tSkin experiment at 12UTC. We obtained an increase of up to $0.2^{\circ} \mathrm{K}$ during afternoon- evening local times, larger differences are seen for the Assim_Sol82 and Assim_PS81 experiments. We attribute these changes to the following three reasons: (i) application of analysis increment in $T_{s}$ (details follow in section 3.3), which was not applied in the tSkin experiment; (ii) tSkin and Assim_Kpar both used (9) for shortwave radiation penetration $\left(S W_{P E N}\right)$, whereas the other two assimilation experiments use different shortwave absorption profiles (table 1); (iii) analysis of AVHRR observations (see section 5.2), not used in tSkin. The difference in the absorbed shortwave radiations equal to $T_{s}(\max )-T_{s}(\min )$ during 00 to 24 hours local mean time. They use hourly output between latitudes $= \pm 40^{\circ}$ for a period of 17 years and show average DSA as a function of averages of $10 \mathrm{~m}$ wind speed and insolation. TBBJ10 and Bellenger and Duvel (2009) also compared their results with empirical estimates based on Gentemann et al. (2003); see TBBJ10 for further details. In an attempt to validate our skin SST model results, we report the April 2012 averaged DSA as a function of $10 \mathrm{~m}$ wind speed and insolation, and between $\pm 60^{\circ}$ latitudes. This is shown in Fig. 8. Because of the relatively small sample size (only 1 month), our figure does not include insolation value of $350 \mathrm{~W} / \mathrm{m}^{2}$ and includes only one data points for up to $10 \mathrm{~ms}^{-1}$ wind speed. All $T_{s}$ assimilation experiments have larger DSA than the tSkin experiment (for most wind speeds and insolation), and the largest was obtained for the Assim_Kpar experiment, particularly at low wind speeds. The DSA for Assim_Kpar peaks to about $3^{\circ} \mathrm{K}$ at $1 \mathrm{~m} / \mathrm{s}$ wind speed and $300 \mathrm{~W} / \mathrm{m}^{2}$ insolation, whereas in the case of TBBJ10 it was about $2.25^{\circ} \mathrm{K}$. Also the rate at which the DSA rises for low wind speed values seems to be too steep. Considering DSA as a function of insolation (right panel of Fig. 8), we obtain a sharper increase between $250-300 \mathrm{~W} / \mathrm{m}^{2}$ and, except for the 
(a) Mean $T_{s}\left({ }^{\circ} \mathrm{K}\right)$ 12UTC. Exp: tSkin

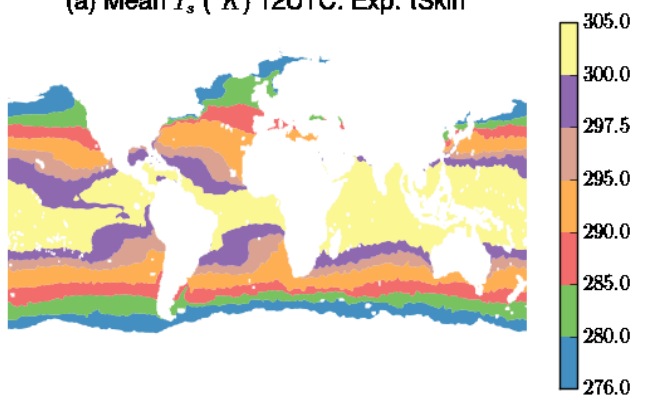

(c) Difference in mean $T_{s}\left({ }^{\circ} \mathrm{K}\right)$. Assim_Sol82 - tSkin

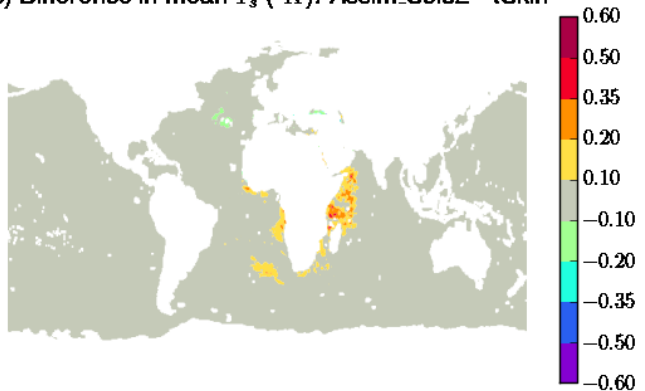

(b) Difference in mean $T_{s}\left({ }^{\circ} K\right)$. Assim Kpar - tSkin

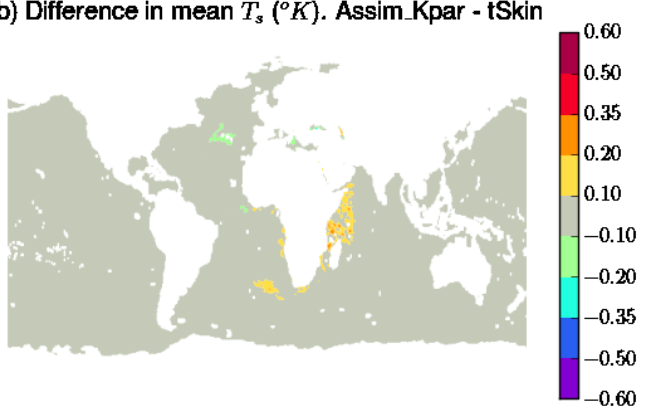

(d) Difference in mean $T_{s}\left({ }^{\circ} K\right)$. Assim_PS81 - tSkin

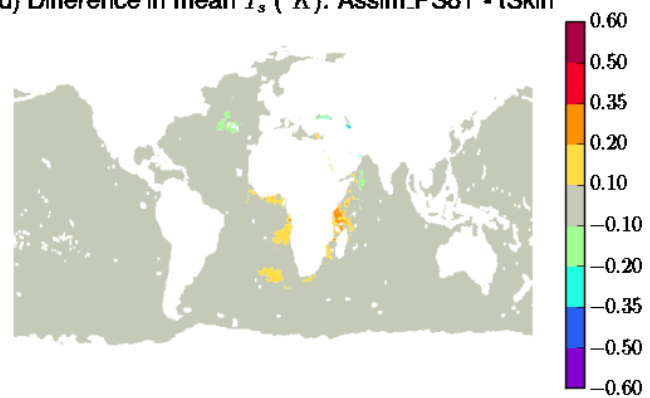

Figure 6. (a) Monthly mean of $T_{s}$ for tSkin experiment at 12UTC. Panels (b)- (d) depict differences from other experiments.

(a) Mean SW" ${ }_{n \text { net }}\left(W^{-a}\right)$. Exp: tSkin

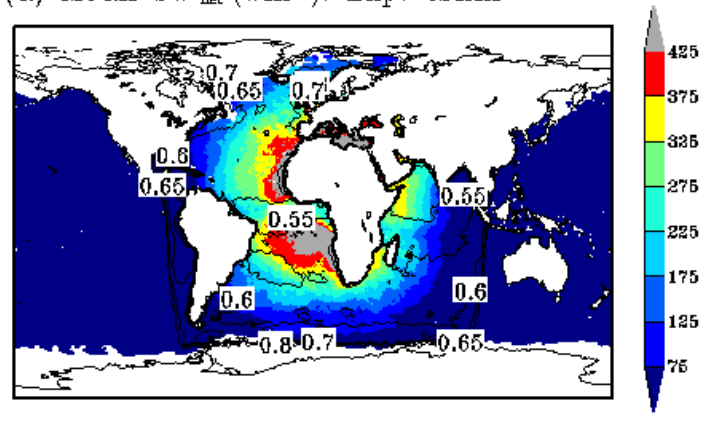

(b) Difference in mean $S W_{\text {not }}\left(W \mathrm{~m}^{-8}\right)$,

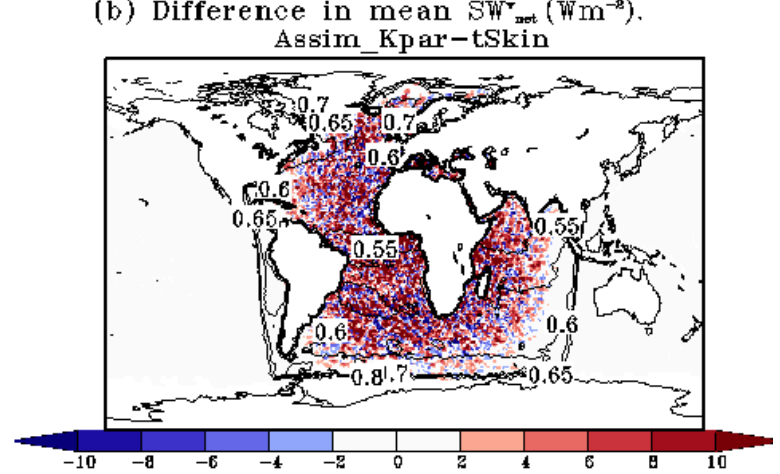

(d) Difference in mean $S W W_{\text {not }}\left(W \mathrm{~m}^{-8}\right)$.

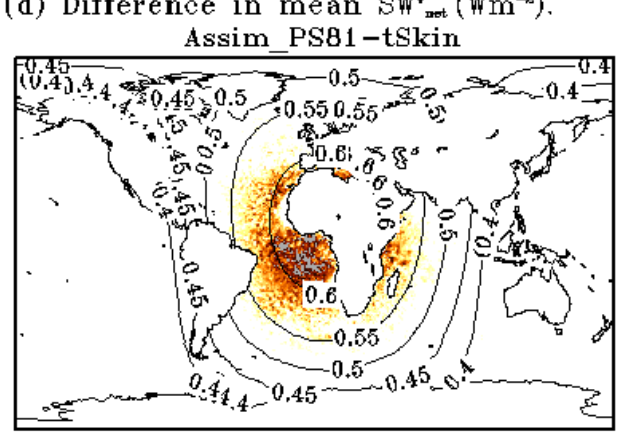

(c) Difference in mean $S W^{*}\left(W \mathrm{~m}^{-8}\right)$.

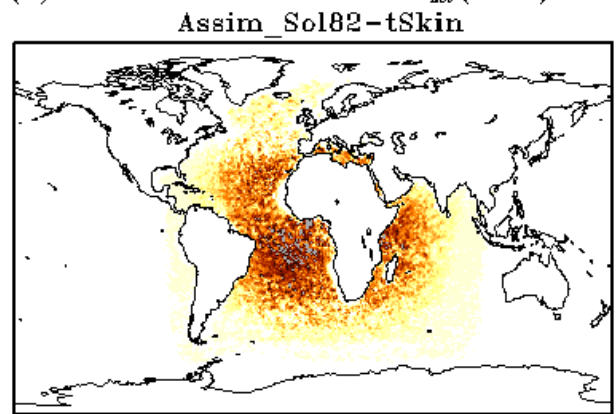

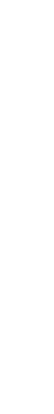
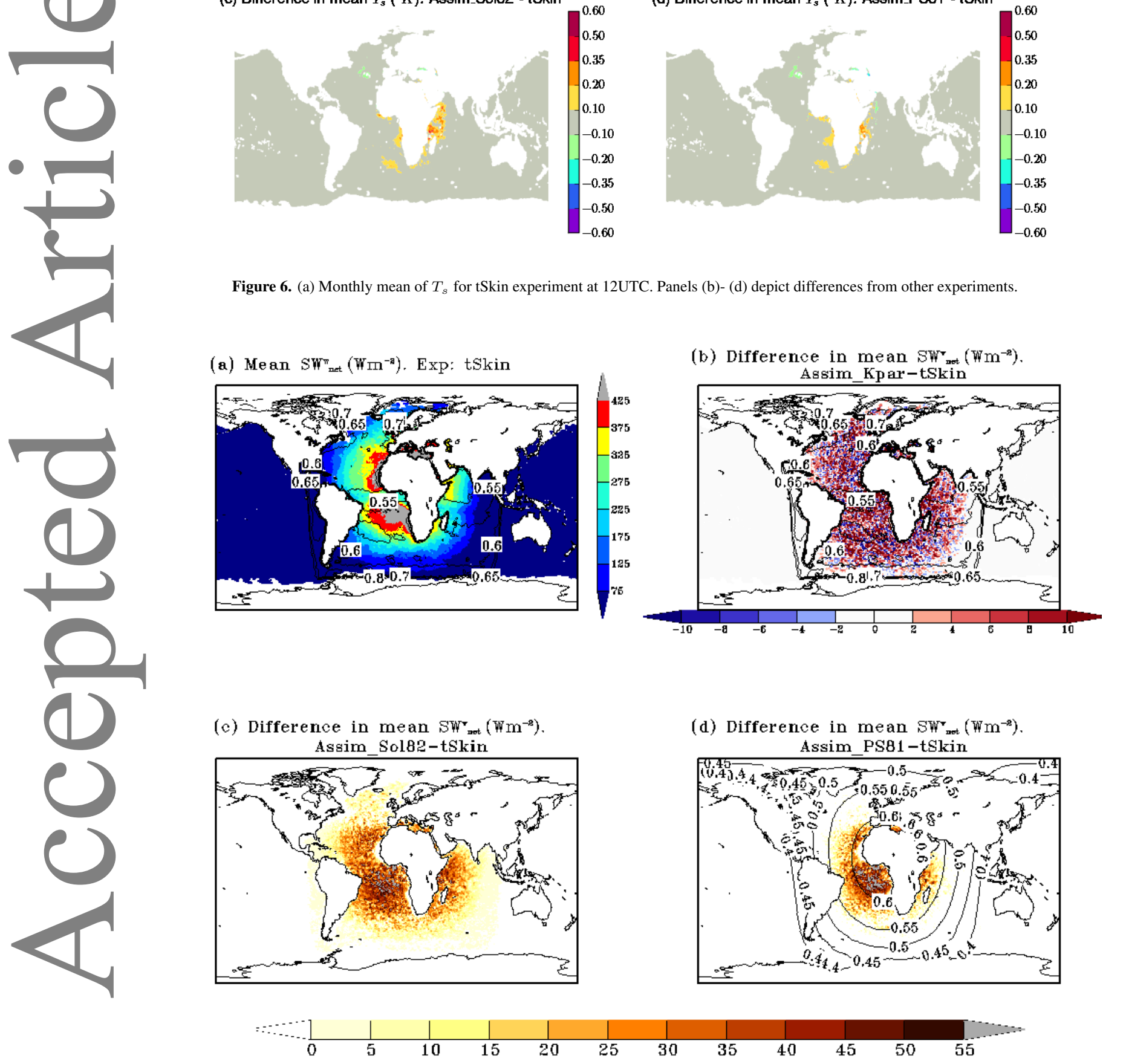

Figure 7. (shaded) Monthly mean of net shortwave radiation absorbed in the diurnal warm layer $\left(S W_{n e t}^{w}\right)$ in $W / m^{2}$ at $12 \mathrm{UTC}$. Contours depict the ratio: $S W_{n e t}^{w} / S W_{n e t}^{s}$. Contours are not shown in panel (c) for the Assim_Sol82 experiment because $S W_{n e t}^{w} / S W_{n e t}^{s}=0.61$ when using the Soloviev (1982) absorption profile at $d=2 m$ depth.

$6 \mathrm{~m} / \mathrm{s}$ wind speed, our DSA values are larger than those obtained by $\mathrm{TBBJ} 10^{\ddagger}$.

\footnotetext{
${ }^{\ddagger}$ We do not include a comparison with Gentemann et al. (2003) empirical estimates, because it arrives at similar conclusions (C. Gentemann, personal communication,
}

Spatial distribution of DSA and the difference among the experiments is shown in Fig. 9. Similar to the differences in $T_{s}$, shown in Fig. 6, $T_{s}$ assimilation experiments have larger DSA 
than tSkin experiment, with peak difference (of about $0.5^{\circ} \mathrm{K}$ ) seen in the Indian ocean. As in the case of the differences in $T_{s}$, we attribute these differences in DSA to the same reasons (that is, application of the $T_{s}$ analysis increment, differences in shortwave absorption and, usage of AVHRR observations). However, DSA of about $3^{\circ} \mathrm{K}$ for low wind speeds and also high values in the Indian Ocean (the maximum DSA reported by TBBJ10 is about $2.5^{\circ} \mathrm{K}$ ) underscores the need to improve our similarity function, turbulent diffusivity (mixing due to surface waves). TBBJ10 also stressed the importance of the accuracy of the Langmuir number $L a$, for diurnal warming calculation; comparison of their DSA with ZB05 shows that the similarity function and $L a$ can significantly impact the maximum DSA. As mentioned in section 2.2, we took a simple approach to calculate $L a$ which lead to a range of $f(L a)$ between unity and roughly 1.6 ; values are comparable to the global constant value used by McLay et al. (2012) who also had no access to a wave model and set $f(L a)=1.4$ globally. Similar issues regarding validation of DSA have also been noted by Takaya et al. (2010b) and McLay et al. (2012). There are limitations to the validation of DSA (please see TBBJ10, sections (4.3 and 4), in section 5.2 we directly compare our near-surface 1 temperature $T(z)$ with withheld in situ SST measurements.

(n)

5.2. Background and analysis departures ( $)$

The GEOS-ADAS assimilates a wide variety of in situ conventional) and satellite (polar orbiting and geostationary) observations. The majority of these data are brightness temperature $\left(T_{b}\right)$ observations (Rienecker et al. 2008; Bosilovich et al. 2015). The overall impact on the analysis of conventional upper-air measured temperature, winds, moisture, and surface pressure for the experiments was minimal when compared to the CTL; change in fit to the observations (mean and standard deviation) is less than $1 \%$. This is probably due to the fact that most of these observations are in the northern hemisphere, on land and are not directly impacted by the skin SST changes considered here.

Drifting buoys (section 3.2) measure near surface SST and are part of the in situ observations that are used in the generation of
SST analyses, such as the OSTIA SST ${ }^{\S}$. They have also been used by Castro et al. (2012) for validation of satellite SST data products; Kennedy et al. (2007) used them to create a climatology of diurnal warming. The GEOS-ADAS does not analyze these observations, but we obtained them from the NOAA/NESDIS iQuam, and used them to validate our near-surface temperature from the tSkin and $T_{s}$ assimilation experiments. Using the highest level of quality controlled observations ( $\mathrm{Xu}$ and Ignatov 2014), and measurement depth $z_{o b}=20 \mathrm{~cm}$ in (10), we calculate the fit of our background fields to these SST observations (using a different value for $z_{o b}$, say $25 \mathrm{~cm}$ did not affect evaluation). The basin averaged mean OMB is shown in Fig. 10. Based on the design of the OSTIA SST analysis (Donlon et al. 2012), observations that could have observed any diurnal warming would not have been analyzed, and if we assimilated them, we would have expected a mean OMB close to zero, hence no diurnal cycle in the OMB. However, since these observations were withheld, the only way we could change our fit to the data was with our skin SST model produced diurnal warming (cool-skin is only about a few millimeters thick, Fig. 4). Indeed we obtained a change in the OMB in the tropics, the most change, as shown in Fig. 10 was obtained in the Indian ocean (region is shown in inset), from morning to afternoon, thereafter our diurnal warming rapidly erodes and the background fit to these observations is almost the same as that for the OSTIA SST (standard deviation of OMB for our experiments and OSTIA SST was within $0.4^{\circ} K$ ). This quick decay of our $\Delta T_{w}$ past sunset is expected to be addressed with the aid of a more realistic Stokes velocity (section 2.2), and also perhaps by following $\mathrm{ZB} 05$ when $Q_{n e t}^{w} \leq 0$; these topics will be addressed in future work.

Fig. 10 also shows that even though the spatial variation of the DSA shown in Fig. 9 for the Indian Ocean was large, yet the fit to the observations is improved (though we do not have observations everywhere). The spikes (less than $-0.2^{\circ} \mathrm{C}$ ) in the fit background to observations on Apr 16 and 18 for Assim_Sol82 and Assim_PS81 are due to the larger background temperature obtained by the corresponding shortwave absorption profiles. The monthly averaged mean and standard deviations of the fit to the

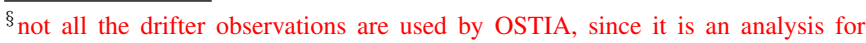
a foundation SST, local daytime observations at low $(<6 \mathrm{~m} / \mathrm{s})$ wind speed are excluded; please see section 3 of (Donlon et al. 2012) for further details 

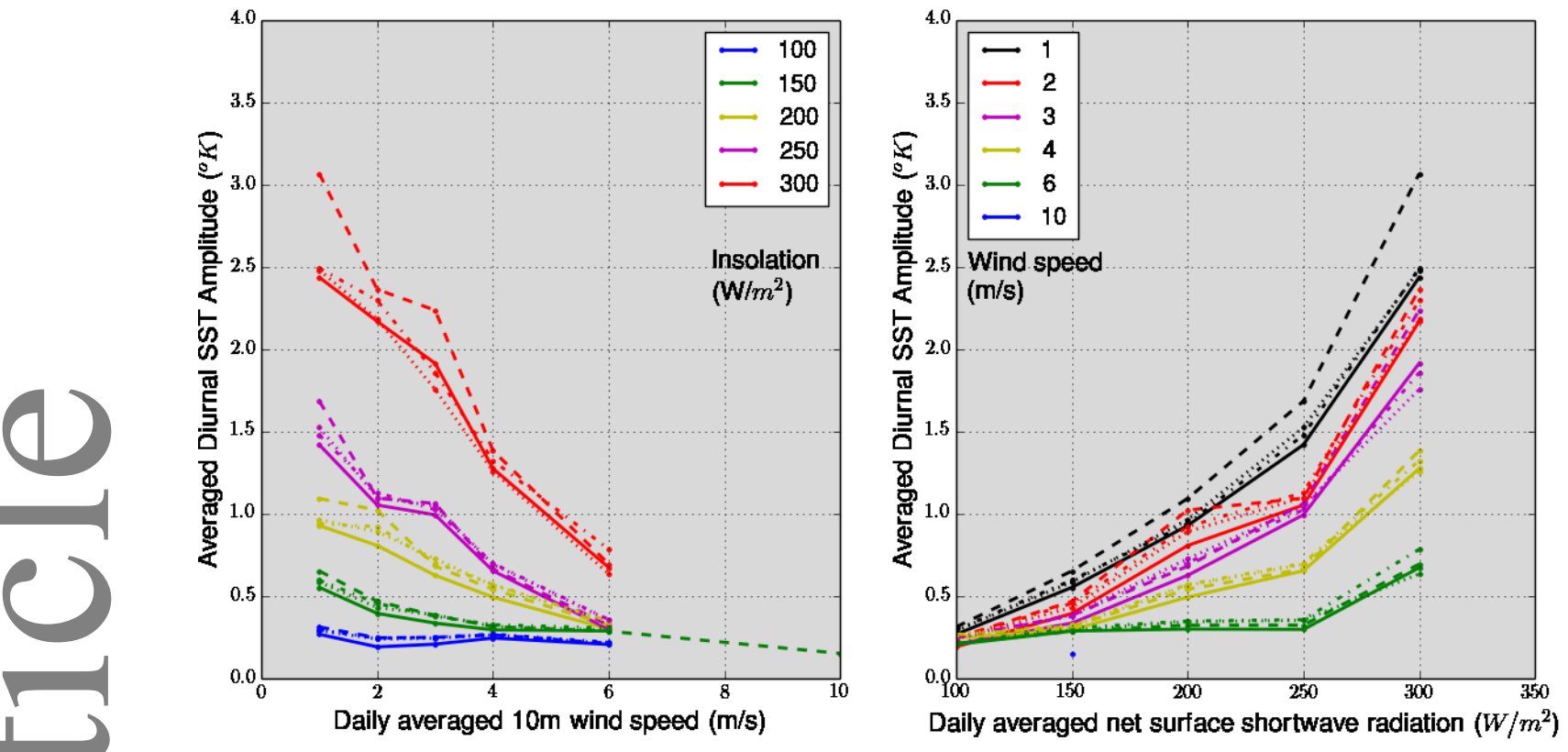

Daily averaged $10 \mathrm{~m}$ wind speed $(\mathrm{m} / \mathrm{s})$

Figure 8. Averaged DSA $\left({ }^{o} K\right)$ as a function of (left) $10 \mathrm{~m}$ wind speed, and (right) insolation for Apr 2012; tSkin experiment is plotted with '-', Assim_Kpar ('- -'), Assim_Sol82 ('-.'), and Assim PS81 (':'). Binning intervals for wind speed and insolation are $0.2 \mathrm{~m} / \mathrm{s}$ and $10 \mathrm{~W} / \mathrm{m}^{2}$ respectively. Data is plotted only if sample size is 100 , average is over the experiment time period.
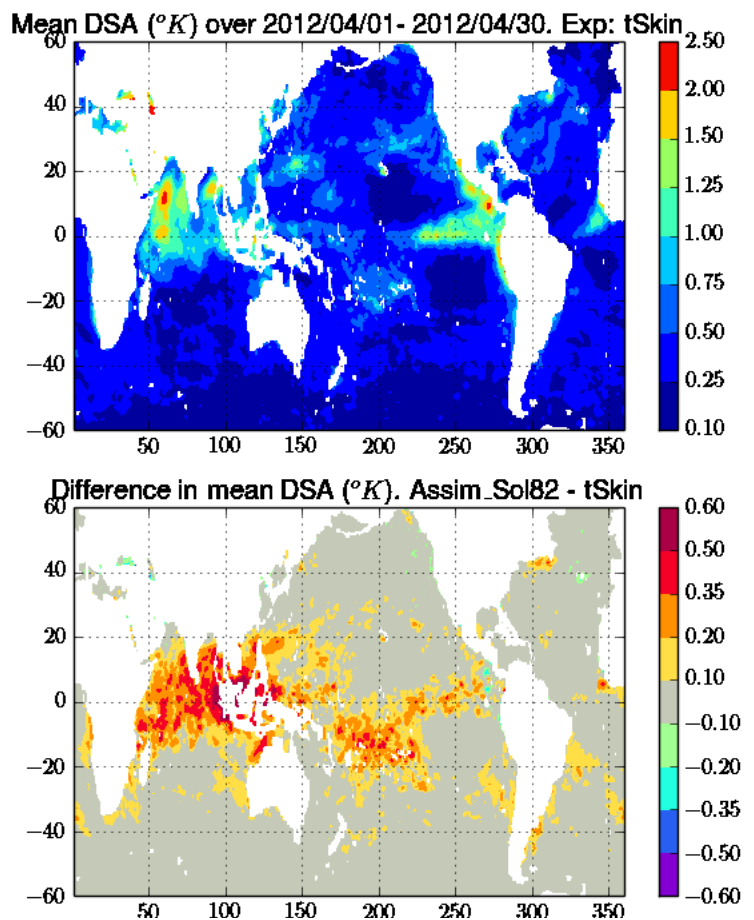
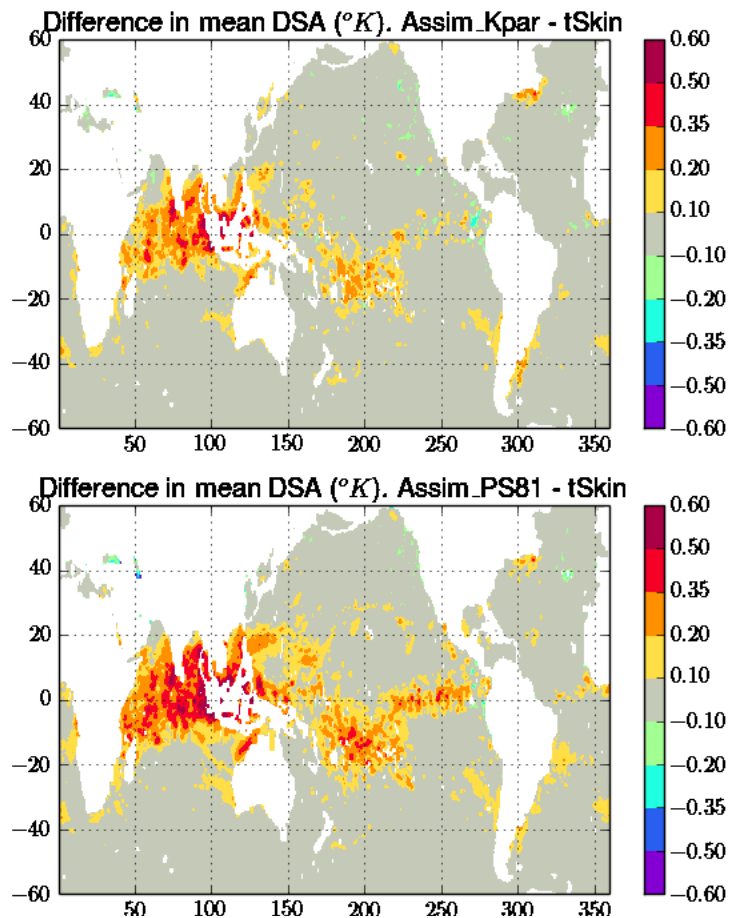

Figure 9. Spatial map of mean DSA $\left({ }^{\circ} K\right)$. Top left panel is for tSkin experiment, all other panels depict differences for other experiments from it.

observations for the different experiments were very similar to each other and showed a small improvement compared to that for OSTIA SST. For example, in the tropical Indian ocean region (Fig. 10), the mean fit of background to observations for OSTIA SST is $0.145^{\circ} K$, and for tSkin, Assim_Kpar, Assim_Sol82, Assim_PS81 it is $0.108^{\circ}, 0.095^{\circ}, 0.088^{\circ}, 0.089^{\circ} K$ respectively. The standard deviation changes by less than $2 \%$ (compared to that for OSTIA SST). Based on these differences between
tSkin and $T_{s}$ assimilation experiments, though the mean fit of background to observations for the assimilation experiments were slightly lower than tSkin (and OSTIA SST), we cannot conclude that the assimilation for $T_{s}$ (and the ensuing air-sea fluxes) significantly improves the fit to these observations than what we obtained without it (as in tSkin). However, these results indicate that our implementation of the TBBJ10 diurnal warming is able to capture part of the diurnal cycle. We arrived at similar conclusions 
based on evaluation with respect to the tropical moored buoys

(TAO/TRITON, PIRATA, RAMA) measured SST at about $1 \mathrm{~m}$.

Our future work will be directed towards assimilating these observations and we hope to obtain better fit to these observations.

We added AVHRR (ocean only observations) to the analysis observing system (section 3.2), the $\mathrm{AVH}$ and $T_{s}$ assimilation experiments assimilated these observations (Table 1). By comparing their AVHRR-OMB we try to assess the impact of skin SST model and $T_{s}$ analysis versus using OSTIA SST.

Fig. 11 shows the April 2012 monthly averaged OMB before any bias correction, for the surface sensitive channel 3 on Metop$\mathrm{A}^{\prime}$ (supposed to measure brightness temperatures at about $15 \mu \mathrm{m}$ below the air-sea interface (11), i.e., in the cool-skin layer). There seems to be a positive impact of the skin SST, and in this case, the cool-skin (this channel is used only during night time when diurnal warming is almost absent), on the OMB as shown in Fig. 11, the $T_{s}$ assimilation experiments have a reduced OMB in the tropics, southern hemisphere and also in the northern hemisphere high latitudes (north Pacific ocean).

Table 2 provides a summary of the OMB statistics for other A AVHRR channels also on Metop-A. As shown in Fig. 11, for channel 3, AVH has a larger OMB before bias correction is applied, hence larger $\left(\sim 0.1^{\circ} K\right)$ mean bias correction than the $T_{s}$ assimilation experiments. For channels 4 and 5, we see a decrease in the OMB in the high latitudes which is offset by increase in the tropics (not shown) thereby yielding a small increase in the mean bias correction for channel 4 and neutral for hannel 5. Overall, for all the experiments the bias corrected mean OMB is close to zero and the standard deviations are below the specified observation error values.

We also obtained minor improvements to the analysis of other IR and MW sensors, that are currently being assimilated in GEOS-ADAS, suggesting a positive synergistic contribution from the skin SST model, assimilation of the AVHRR observations and usage of $T_{s}$ analysis increment. For example, the OMB (before bias correction) for channel 123 of the atmospheric infrared sounder (AIRS) on the AQUA satellite (a surface sensitive window channel, measuring at about 11.8 micro-meters wavelength), for the CTL and AVH were alike. However, tSkin and $T_{s}$ assimilation experiments have a reduced cold bias in the
Table 2. Comparison of mean OMB statistics (in ${ }^{o} K$ ) for the AVHRR observations on board Metop-A for the AVH and $T_{s}$ assimilation experiments Specified value of observational error standard deviation (SDEV) for each channel is given by $\sigma_{o}$. The average number of observations (Nobs), mean and SDEV of bias corrected OMB and mean bias correction are calculated using all the analyses within the experiment time period. Channel 3 is used during local nighttime only, hence the smaller number of observations than for channels 4 and 5 .

\begin{tabular}{lllll}
\hline Exp. Name & Nobs & Mean & SDEV & Mean Bias Corr \\
\hline & Ch.3 & & $\sigma_{o}=0.6^{\circ} K$ & \\
\hline AVH & 1054 & -0.041 & 0.324 & 0.212 \\
Assim_Kpar & 1079 & 0.014 & 0.330 & 0.109 \\
Assim_Sol82 & 1080 & 0.016 & 0.331 & 0.113 \\
Assim_PS81 & 1080 & 0.015 & 0.330 & 0.109 \\
\hline & Ch.4 & & $\sigma_{o}=0.68^{\circ} K$ & \\
\hline AVH & 2267 & 0.030 & 0.424 & -0.041 \\
Assim_Kpar & 2314 & 0.048 & 0.429 & -0.106 \\
Assim_Sol82 & 2316 & 0.047 & 0.428 & -0.106 \\
Assim_PS81 & 2316 & 0.046 & 0.428 & -0.108 \\
\hline & Ch.5 & & $\sigma_{o}=0.72^{\circ} K$ & \\
\hline AVH & 2545 & 0.086 & 0.534 & 0.036 \\
Assim_Kpar & 2596 & 0.097 & 0.538 & -0.014 \\
Assim_Sol82 & 2599 & 0.097 & 0.538 & -0.015 \\
Assim_PS81 & 2597 & 0.095 & 0.537 & -0.016 \\
\hline
\end{tabular}

OMB in the southern oceans and northern Pacific (not shown; please see Akella et al. (2016)). Besides a small reduction in mean bias for these surface sensitive window channels, we also obtained a reduction in the standard deviation for the water vapor sensitive and lower troposphere peaking channels as well, as shown in Fig. 12 for the infrared atmospheric sounding interferometer (IASI) on Metop-A. For IASI, just as with AIRS, the reduction in standard deviation is larger for the Assim_Kpar and Assim_PS81 than the tSkin experiment, whereas AVH did not show any change from the CTL. For the Assim_Sol82 experiment, there is a decrease of about $0.1^{\circ} \mathrm{K}$ in standard deviation for the water vapor and surface sensitive channels, and an increase of similar magnitude for the stratospheric and tropospheric (upper and lower) sensitive channels. Further studies that focus on the channels that peak at higher in altitude (stratosphere, troposphere) are required to investigate this behavior with the Soloviev (1982) shortwave absorption profile.

\section{3. $T_{s}$ Analysis Increments}

Analysis increments provide observational feedback to the model trajectory through IAU (Bloom et al. 1996), and are available at synoptic times (Rienecker et al. (2008); section 3). The monthly averaged analysis increment (12 UTC analyses) in $T_{s}$ is shown in Fig.13. These increments are fed back to the model 
(a)

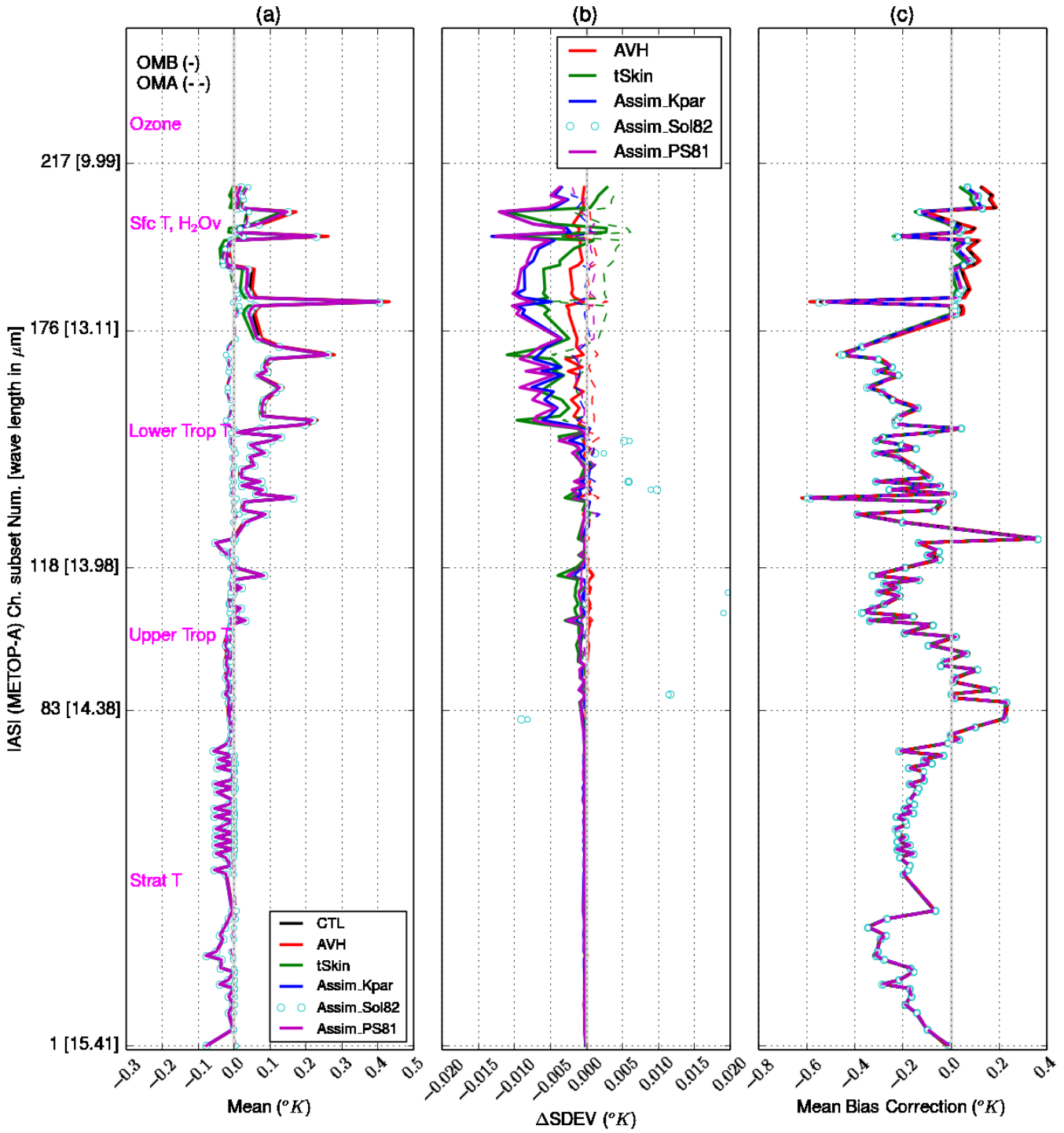

(d)

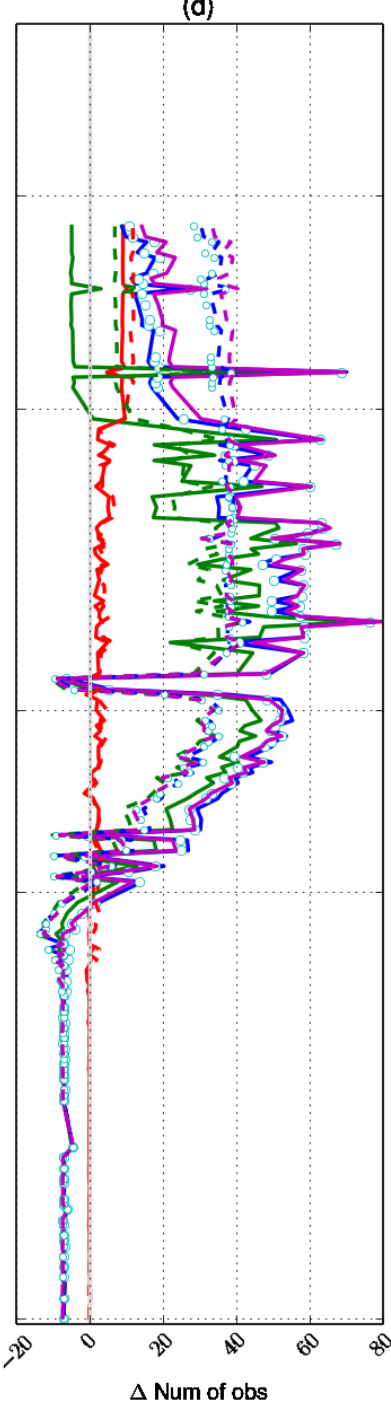

Figure 12. Monthly averaged OMB statistics for the the IASI on Metop-A satellite; statistics computed only over water. (left to right) Panels (a) and (c) show the mean bias corrected OMB and mean bias correction (defined in Table 2); (c) and (d) depict the difference (from CTL) in the bias corrected standard deviation (SDEV) of OMB and number of observations respectively. The ordinate is same for all panels, is shown in (a). Solid (dashed) lines are for OMB (OMA). Panel (a) shows the approximate regions of the atmosphere where channels peak.

in the southern hemisphere extratropics (SHE) forecasts from the Assim_Kpar have the highest ACOR, followed by other experiments. Figure 14 shows the ACOR for the SHE global geopotential height field at $850 \mathrm{hPa}$; skills for other variables were marginally better and any improvements in the skill diminished with increasing height.

\section{Summary and conclusions}

Skin SST is very important for air-sea interaction and in the GEOS-5 ADAS it is currently specified from an already existing daily OSTIA SST product. This prescription of the skin SST neglects a considerable variability in the diurnal cycle and the very thin cool skin layer in contact with the atmosphere, that is observed by radiometric and in situ observations taken close to the sea surface. The present work updates the GEOS-5 ADAS skin SST formulation by incorporating these effects in the model in an attempt to obtain a realistic evolution of $T_{s}$ and focussed on its estimation by analysis and assimilation of near surface SST relevant observations.

A skin SST model was added to the air-sea interface component of the AGCM to prognostically compute: (i) a diurnal warming, mostly based on ZB05 and TBBJ10, and (ii) a diagnostic coolskin layer following F96. Both of these effects are applied on top of the OSTIA SST, and the latter is taken as a foundation SST.

We adapt the TBBJ10 diurnal warming model, with the following three modifications. First, due to the absence of a wave model, we used a global constant value for the surface Stokes velocity. Second (due to the first reason), we chose not to follow the $\mathrm{ZB} 05 / \mathrm{TBBJ} 10$ procedure to simulate the slow decay of diurnal warming in the late afternoon- evening local time. We 
AVH experiment was designed to test the impact of AVHRR observations only, tSkin tested the impact of the skin SST model only, and finally three $T_{s}$ assimilation experiments combined all the updates (active skin SST model, AVHRR observations, and $T_{s}$ analysis increment feedback to the AGCM); they differ only in the shortwave absorption models.

As a result of the cool skin layer model, the amount of cooling is inversely proportional to the wind speed, minimum and maximum values of cooling are about $0.05^{\circ}$ and $0.5^{\circ} \mathrm{K}$ respectively. The diurnal variation in the net heat flux produce a naximum variability of about $0.2^{\circ} \mathrm{K}$ in areas with large insolation and low wind speed (e.g., Indian Ocean). By comparing the tSkin and $T_{s}$ assimilation experiments, we notice a very small impact (less than $0.02^{\circ} \mathrm{K}$ ) on cool skin layer. The maximum diurnal warming is about $2^{\circ} \mathrm{K}$ in the tropical oceans and it is lower in the extratropics. The peak warming occurs about 2 to 3 hours after local noon time, which is similar to that obtained by ZB05, TBBJ10 and observations reported by F96. But due to the differences between our diurnal model implementation TBBJ10 mentioned above, we obtain a quick erosion of our diurnal warming after sunset, indicating an excessive amount of dissipation. We also obtain a DSA of about $2.5^{\circ}-3^{\circ} \mathrm{K}$ at low wind speeds, as in ZB05, but about $0.5-1^{\circ} \mathrm{K}$ more than TBBJ10. Considering figure 3 of TBBJ10, this may also be related to our simplification of the Stokes velocity; however, DSA is not directly measured and there are uncertainties in its estimation. Overall, the difference between skin and OSTIA SST is between $-0.6^{\circ}$ to $1.5^{\circ} \mathrm{K}$. The difference between tSkin and $T_{s}$ assimilation experiments was about $0.2^{\circ} \mathrm{K}$ in the late afternoon to evening local times.

We evaluate the temperature within the diurnal warming layer by using withheld SST observations from drifting buoys. The fit to the observations is also compared with the observationminus-OSTIA SST, because the latter is a foundation SST, hence serves as a reference. The calculated temperature is closer to the observations; in the tropics, particularly the Indian Ocean, where we obtain large diurnal warming, the morning to afternoon (rising part of the diurnal cycle) fit to the observations was lower than that for OSTIA SST. However, the late afternoon- evening part of the diurnal cycle does not show any improvement due to rapid erosion of our diurnal warming. Differences between tSkin and $T_{s}$ assimilation experiments are small. Weaker diurnal cycle outside of the tropics lead to an insignificant change in the fit to the observations.

OMB statistics for satellite observations show a decrease in the mean bias with the usage of the skin SST model; there is a systematic improvement in the simulated brightness temperature. In particular, the OMB for hyperspectral IR instruments (AIRS and IASI) also reveals a positive feedback from the skin SST and combination of assimilating AVHRR and $T_{s}$ increment. The fit to the surface as well as the water vapor sensitive channels is improved for both tSkin and $T_{s}$ assimilation experiments, with more benefit in the latter experiments; changes are insignificant for the AVH experiment. Feedback of the analysis increment in skin SST to the AGCM led to lower increments in skin SST in the $T_{s}$ assimilation experiments, perhaps indicates a more selfconsistent ADAS. Since the $T_{s}$ analysis is univariate, there was no noticeable difference in the analysis increments of other analyzed variables.

The impact on the predictability of the model is mostly neutral. Among our experiments, the combination of all changes and shortwave absorption that included turbidity via PAR flux (Assim_Kpar experiment) show the best forecast skill scores, up to 5-days lead time. Statistically significant improvements are obtained in the southern hemisphere, close to the surface and, the significance diminished with altitude.

In summary, we acknowledge some drawbacks such as the rapid erosion of diurnal warming just after dawn and high sensitivity to low wind speed, which will be addressed by future improvements. We also plan to evaluate the impact on air-sea fluxes and near-surface climatology in our future work. Overall, our diagnostics indicate that the range of our skin SST, its spatial distribution and diurnal variation are comparable to the values reported by F96, ZB05, and TBBJ10 and also seem to improve fit to observed in situ and satellite observations.

Using an ocean mixed layer model to resolve the SST diurnal cycle in the ECMWF operational system Takaya et al. (2010b) obtained improvements in 3- 5 days ACOR of temperature (at lower levels, for e.g., 1000, $850 \mathrm{hPa}$ ), but they were statistically insignificant, also they reported no difference 
in $500 \mathrm{hPa}$ geopotential height ACOR. Conclusions based on our results using GEOS-ADAS cannot be extrapolated to the performance of other systems, since our forecasts are self-verified. However, Takaya et al. (2010b) (on pp.27) stress the importance of coupling between SST and errors in air-sea fluxes. In that regard, modeling for the skin SST and direct assimilation SST relevant observations, offers an opportunity to explicitly account for SST errors, and air-sea interface fluxes; and that was exactly the goal of our $T_{s}$ assimilation experiments, which show the most positive results among other experiments considered here.

This point is reinforced by the work of McLay et al. (2012) in' the US Navy NOGAPS operational ADAS system, which included an SST diurnal cycle and perturbations for SST analyses (in an ensemble data assimilation framework), taking a step in the direction of explcitly accounting for synoptic-scale local SST variability. Based on forecasts up to lead times of 10 to 14 days they report statistically significant improvements in skin temperature (land and sea), 2-m air temperature, $10 \mathrm{~m}$ wind speed, $500 \mathrm{hPa}$ geopotential heights and daily accumulated precipitation. Taking into consideration results of Takaya et al. (2010b); 4 McLay et al. (2012) and ours (in GEOS-ADAS), incorporating related modifications to the SST, mostly lead to positive 1 improvements in the forecasts. Further revisit of skin SST modeling, air-sea fluxes, coupling with a wave model, tuning of atmospheric boundary layers, modeling of the observational and background errors (using ensemble methods) should be pursed along with the incorporation of MW and in situ SST observations the context of the development of a coupled data assimilation system.

\section{Acknowledgement}

This work was partially funded by NASA ROSES 2010, NNH10ZDA001N-MAP. We thank Michele Rienecker for her initial guidance. $\mathrm{Xu} \mathrm{Li}$ and John Derber are thanked for sharing their initial development within the GSI. We thank Chelle Gentemann for helpful suggestions and diagnostics performed on our diurnal warming model, Xubin Zeng and Anton Beljaars for sharing their diurnal model and helping with evaluation of results. We thank F. Xu and Alex Ignatov for making the iQuam data set publicly available. Thanks are also due to
Will McCarty and Meta Sienkiewicz for their help with satellite bias correction and radiative transfer; Lawrence Takacs for help with the forecast verification and Chris Fairall for suggestions on the bulk to skin temperature modeling. Computations were performed at NASA NCCS.

\section{References}

Akella S, Todling R, Suarez M. 2016. Estimation of the ocean skin temperature using the NASA GEOS Atmospheric Data Assimilation System. Technical Report Series on Global Modeling and Data Assimilation NASA/TM-2016-104606/Vol 44, NASA Goddard Space Flight Center.

Beljaars ACM. 1997. Air-sea interaction in the ECMWF model. Seminar on Atmosphere-Surface Interactions. ECMWF, Reading, U. K.

Bellenger H, Duvel JP. 2009. An analysis of tropical ocean diurnal warm layers. J. Climate 22: 3629-3646, doi:10.1175/ 2008JCLI2598.1.

Bloom SC, Takacs LL, da Silva AM, Ledvina D. 1996. Data assimilation using incremental analysis updates. Mon Weather Rev 124: 1256-1271.

Bosilovich MG, Akella S, Coy L, Cullather R, Draper C, Gelaro R, Kovach R, Liu Q, Molod A, Norris P, Wargan K, Chao W, Reichle R, Takacs L, Vikhliaev Y, Bloom S, Collow A, Firth S, Labow G, Partyka G, Pawson S, Reale O, Schubert SD, Suarez M. 2015. MERRA-2: Initial evaluation of the climate. Technical Report Series on Global Modeling and Data Assimilation NASA/TM-2015-104606/Vol 43, NASA Goddard Space Flight Center.

Brassington GB, Martin MJ, Tolman HL, Akella S, Balmeseda M, Chambers CRS, Chassignet E, Cummings JA, Drillet Y, Jansen PAEM, Laloyaux P, Lea D, Mehra A, Mirouze I, Ritchie H, Samson G, Sandery PA, Smith GC, Suarez M, Todling R. 2015. Progress and challenges in short- to medium-range coupled prediction. J Operational Oceanography. 8: s239- s258, doi: 10.1080/1755876X.2015.1049875.

Brunke MA, Zeng X, Misra V, Beljaars A. 2008. Integration of a prognostic sea surface skin temperature scheme into weather and climate models. J Geophys Res-Atmos 113: D21 117, doi: 10.1029/2008JD010607. 
Castro SL, Wick GA, Emery WJ. 2012. Evaluation of the relative performance of sea surface temperature measurements from different types of drifting and moored buoys using satellite-derived reference products. J Geophys Res-Oceans 117: C02 029, doi:10.1029/2011JC007472.

Castro SL, Wick GA, Jackson DL, Emery WJ. 2008. Error characterization of infrared and microwave satellite sea surface temperature products for merging and analysis. J Geophys Res 113: C03 010, doi:10.1029/2006JC003829.

Chen Y, Han Y, Delst PV, Weng F. 2010. On water vapor Jacobian in fast radiative transfer model. J Geophys Res 115: D12 303, doi:10.1029/2009JD013379.

Chen Y, Han Y, Weng F. 2012. Comparison of two transmittance algorithms in the community radiative transfer model: Application to AVHRR. J Geophys Res-Atmos 117: D06206, doi:10.1029/2011JD016656.

rry JA, Bentamy A, Bourassa MA, Bourras D, Bradley EF, Brunke M, Castro S, Chou SH, Clayson CA, Emery WJ, Eymard L, Fairall CW, Kubota M, Lin B, Perrie W, Reeder RA, Renfrew IA, Rossow WB, Rossow WB, Schulz J, Smith SR, Webster PJ, Wick GA, Zeng X. 2004. Seaflux. Bull. Amer. Meteor. Soc. 85: 409-424, doi:http://dx.doi.org/10.1175/ BAMS-85-3-409.

Dee D, Uppala S. 2009. Variational bias correction of satellite radiance data in the ERA-interim reanalysis. Q. J. R. Meteorol. Soc. 135: 1830- 1841, doi:10.1002/qj.493.

Dee DP, Balmaseda M, Balsamo G, Engelen R, Simmons AJ, Thépaut JN. 2014. Toward a consistent reanalysis of the climate system. Bull. Amer. Meteor. Soc. 95: 1235-1248, doi:http://dx. doi.org/10.1175/BAMS-D-13-00043.1.

Derber JC, Wu WS. 1998. The use of TOVS CloudCleared Radiances in the NCEP SSI analysis system. Mon Weather Rev 126: 2287- 2299, doi:http://dx.doi.org/10.1175/ 1520-0493(1998)126<2287:TUOTCC $>2.0 . C O ; 2$.

Donlon C, Minnett PJ, Gentemann C, Nightingale TJ, Barton IJ, Ward B, Murray MJ. 2002. Toward improved validation of satellite sea surface skin temperature measurements for climate research. J. Climate 15: 353-369.
Donlon C, Robinson I, Casey KS, Vazquez-Ciervo J, Armstrong E, Arino O, Gentemann C, May D, Le Borgne P, Piollé J, Barton I, Beggs H, Poulter DJS, Merchant CJ, Bingham A, Heinz S, Harris A, Wick G, Emery B, Minnett P, Evans R, Llewellyn-Jones D, Mutlow C, Reynolds RW, Kawamura H, Rayner N. 2007. The global ocean data assimilation experiment high-resolution sea surface temperature pilot project. Bull. Amer. Meteor. Soc 88: 1197-1213, doi:http://dx.doi.org/10. 1175/BAMS-88-8-1197.

Donlon CJ, Martin M, Stark J, Roberts-Jones J, Fiedler E, Wimmer W. 2012. The Operational Sea Surface Temperature and Sea Ice Analysis (OSTIA) system. Remote Sens. Environ. 116: 140-158, doi:10.1016/j.rse.2010.10.017.

Eyre JR. 2016. Observation bias correction schemes in data assimilation systems: a theoretical study of some of their properties. Q. J. R. Meteorol. Soc. 142: 2284- 2291, doi:10. 1002/qj.2819.

Fairall CW, Bradley EF, Godfrey JS, Wick GA, Edson JB, Young GS. 1996. Cool-skin and warm-layer effects on sea surface temperature. J Geophys Res-Oceans 101: 1295-1308, doi:10. 1029/95JC03190.

Filipiak MJ, Merchant CJ, Kettle H, Borgne PL. 2010. A statistical model for sea surface diurnal warming driven by numerical weather prediction fluxes and winds. Ocean Sci. Discuss. 7: 1497-1532, doi:10.5194/osd-7-1497-2010.

Gentemann CL, Donlon CJ, Stuart-Menteth A, Wentz FJ. 2003. Diurnal signals in satellite sea surface temperature measurements. Geophys. Res. Lett. 30: 1140, doi:10.1029/ 2002 GL016291.

Gentemann CL, Minnett PJ. 2008. Radiometric measurements of ocean surface thermal variability. J. Geophys. Res. 113: C08 017, doi:10.1029/2007JC004540.

Gentemann CL, Minnett PJ, Ward B. 2009. Profiles of ocean surface heating (POSH): A new model of upper ocean diurnal warming. J. Geophys. Res. 114: C07 017, doi:10.1029/ 2008JC004825.

Ham YG, Rienecker MM, Suarez MJ, Vikhliaev Y, Zhao B, Marshak J, Vernieres G, Schubert SD. 2014. Decadal prediction 
skill in the GEOS-5 forecast system. Clim Dyn 42: 1-20, doi: 10.1007/s00382-013-1858-x.

Han Y, van Delst P, Liu Q, Weng F, Yan B, Treadon R, Derber J. 2006. JCSDA Community Radiative Transfer Model (CRTM)version 1. NOAA Technical Report NESDIS 122, U.S. Dept of Commerce, NOAA, Washington, D.C.

Hosoda K. 2010. A review of satellite-based microwave observations of Sea Surface Temperatures. J Oceanogr 66: 439-473.

Kawai Y, Wada A. 2007. Diurnal Sea Surface Temperature variation and its impact on the Atmosphere and Ocean: A Review. J Oceanogr 63: 721-744.

Kennedy JJ, Brohan P, Tett SFB. 2007. A global climatology of the diurnal variations in sea-surface temperature and implications for MSU temperature trends. Geophys. Res. Lett. 34: L05 712, doi:10.1029/2006GL028920.

Kleist DT, Parrish DF, Derber JC, Treadon R, Errico RM, Yang R. 2009a. Improving incremental balance in the GSI 3DVAR analysis system. Mon Weather Rev 137: 1046-1060, doi:10. 1175/2008MWR2623.1.

Kleist DT, Parrish DF, Derber JC, Treadon R, Wu WS, Lord S. 2009b. Introduction of the GSI into the NCEP Global Data Assimilation System. Wea. Forecasting 24: 1691-1705, doi: http;//dx.doi.org/10.1175/2009WAF2222201.1.

Laloyaux P, Balmaseda MA, Dee D, Mogensen K, Janssen P. 2016a. A coupled data assimilation system for climate reanalysis. Q. J. R. Meteorol. Soc. 142: 65- 78, doi:10.1002/ qj. 2629.

Laloyaux P, Thépaut JN, Dee D. 2016b. Impact of scatterometer surface wind data in the ECMWF coupled assimilation system. Mon Weather Rev 144: 1203-1217, doi:http://dx.doi.org/10. 1175/MWR-D-15-0084.1.

Lea DJ, Mirouze I, Martin MJ, King RR, Hines A, Walters D, Thurlow M. 2015. Assessing a new coupled data assimilation system based on the Met Office coupled atmosphere-landocean-sea ice model. Mon Weather Rev 143: 4678-4694, doi: http://dx.doi.org/10.1175/MWR-D-15-0174.1.
Liang XM, Ignatov A, Kihali Y. 2009. Implementation of the Community Radiative Transfer Model in Advanced ClearSky Processor for oceans and validation against nightime AVHRR radiances. J. Geophys. Res. 114: D06 112, doi:10. 1029/2008JD010960.

Lumpkin R, Pazos M. 2007. Measuring surface currents with surface velocity program drifters: The instrument, its data and some results., ch. 2. Lagrangian Analysis and Prediction of Coastal and Ocean Dynamics (LAPCOD), Cambridge University Press, pp. 39- 67, doi:http://dx.doi.org/10.1017/ CBO9780511535901.003.

May DA, Parmeter MM, Olszewski DS, McKenzie BD. 1998. Operational processing of Satellite Sea Surface Temperature retrievals at the Naval Oceanographic Office. Bull. Amer. Meteor. Soc. 79: 397- 407, doi:http://dx.doi.org/10.1175/ 1520-0477(1998)079<0397:OPOSSS $\rangle$ 2.0.CO;2.

May DA, Stowe LL, Hawkins JD, McClain EP. 1992. A correlation of Saharan dust effects on satellite sea surface temperature measurements. J Geophys Res 97: 3611-3619.

McLay JG, Flatau MK, Reynolds CA, Cummings J, Hogan T, Flatau PJ. 2012. Inclusion of sea-surface temperature variation in the U.S. Navy ensemble-transform global ensemble prediction system. J. Geophys. Res. 117: D19 120, doi:10.1029/ 2011JD016937.

Merchant CJ, Embury O, Le Borgne P, Bellec B. 2006. Saharan dust in nighttime thermal imagery: Detection and reduction of related biases in retrieved sea surface temperature. Remote Sens. Environ. 104: 15- 30, doi:10.1016/j.rse.2006.03.007.

Molod A, Takacs L, Suarez M, Bacmeister J, Song IS, Eichmann A. 2012. The GEOS-5 Atmospheric General Circulation Model: Mean Climate and Development from MERRA to Fortuna. Technical Report Series on Global Modeling and Data Assimilation NASA/TM-2012-104606/Vol 28, NASA Goddard Space Flight Center.

Morel A, Huot Y, Gentili B, Werdell PJ, Hooker SB, Franz BA. 2007. Examining the consistency of products derived from various ocean color sensors in open ocean (Case 1) waters in the perspective of a multi-sensor approach. Remote Sens. Environ. 111: 69- 88, doi:10.1016/j.rse.2007.03.012.

This article is protected by copyright. All rights reserved. 
Ohlmann JC. 2003. Ocean radiant heating in climate models.

J. Climate 16: 1337- 1351, doi:http://dx.doi.org/10.1175/ 1520-0442-16.9.1337.

Ohlmann JC, Siegel DA. 2000. Ocean radiant heating. Part II: Paramterizing solar radiation transmission through the upper ocean. J Phys Oceanogr 30: 1849-1865.

Paulson CA, Simpson JJ. 1981. The temperature difference across the cool skin of the ocean. J. Geophys. Res. 86(C11), doi: 10.1029/JC086iC11p11044.

Putman WM, Lin SJ. 2007. Finite-volume transport on various cubed-sphere grids. J Comput Phys 227: 55-78, doi:10.1016/j. jcp.2007.07.022.

Reynolds RW, Rayner NA, Smith TM, Stokes DC, Wang Q. 2002. An improved in situ and satellite SST analysis for climate. $J$. Climate 15: 1609-1625.

Reynolds RW, Smith TM, Liu C, Chelton DB, Casey KS, Schlax MG. 2007. Daily high-resolution-blended analyses for Sea Surface Temperature. J. Climate 20: 5473-5496, doi:10.1175/ 2007JCLI1824.1.

Rienecker MM, Suarez M, Todling R, Bacmeister J, Takacs L, Ciu HC, Gu W, Sienkiewicz M, Koster RD, Gelaro R, Stajner I, Nielsen JE. 2008. The GEOS-5 Data Assimilation System. Documentation of versions 5.0.1 and 5.1.0, and 5.2.0. Technical Report Series on Global Modeling and Data Assimilation NASA/TM-2008-104606/Vol 27, NASA Goddard Space Flight Center.

Rienecker MM, Suarez MJ, Gelaro R, Todling R, Bacmeister J, Liu E, Bosilovich MG, Schubert SD, Takacs L, Kim GK, Bloom S, Chen J, Collins D, Conaty A, da Silva A, Gu W, Joiner J, Koster RD, Lucchesi R, Molod A, Owens T, Pawson S, Pegion P, Redder C, Reichle R, Robertson FR, Ruddick AG, Sienkiewicz M, Woollen J. 2011. MERRA: NASAs ModernEra Retrospective Analysis for Research and Applications. J. Climate 24: 3624-3648, doi:10.1175/JCLI-D-11-00015.1.

Saunders PM. 1967. The Temperature at the Ocean-Air Interface. J Atmos Sci 24: 269-273.

Soloviev A, Lukas R. 1997. Observation of large diurnal warming events in the near-surface layer of the western equatorial Pacific warm pool. Deep-Sea Res 44: 1055-1076.
Soloviev AV. 1982. On the vertical structure of the ocean thin surface layer at light wind. Dokl. Acad. Sci. USSR Earth Sci. Sect. Engl. Transl. 18: 751-760.

Takaya Y, Bidlot JR, Beljaars ACM, Janssen PAEM. 2010a. Refinements to a prognostic scheme of skin sea surface temperature. J Geophys Res-Oceans 115: C06009, doi:10. 1029/2009JC005985.

Takaya Y, Vitart F, Balsamo G, Balmaseda M, Leutbecher M, Molteni F. 2010b. Implementation of an ocean mixed layer model in IFS. Technical Memorandum 622, European Centre for Medium-Range Weather Forecasts, Shinfield Park, Reading, RG2 9AX, England, URL http: //www. ecmwf. int/publications/.

Vernieres G, Rienecker MM, Kovach R, Keppenne CL. 2012. The GEOS-iODAS: Description and Evaluation. Technical Report Series on Global Modeling and Data Assimilation NASA/TM2012-104606/Vol 30, NASA Goddard Space Flight Center.

Ward B. 2006. Near-surface ocean temperature. J. Geophys. Res. 111: C02 004, doi:10.1029/2004JC002689.

Webster PJ, Clayson CA, Curry JA. 1996. Clouds, radiation and the diurnal cycle of sea surface temperature in the tropical western Pacific. J. Climate 9: 1712- 1730, doi:http://dx.doi.org/ 10.1175/1520-0442(1996)009〈1712:CRATDC $\rangle$ 2.0.CO;2.

While J, Martin M. 2013. Development of a variational data assimilation system for the diurnal cycle of sea surface temperature. J Geophys Res-Oceans 118: 2845-2862, doi:doi: 10.1002/jgrc.20215.

Wick GA, Ohlmann JC, Fairall CW, Jessup AT. 2005. Improved oceanic cool-skin corrections using a refined solar penetration model. J Phys Oceanogr 35: 1986-1996.

Wieliczka DM, Weng S, Querry MR. 1989. Wedge shaped cell for highly absorbent liquids: infrared optical constants of water. Appl Optics 28: 1714- 1719.

Xu F, Ignatov A. 2014. In situ SST Quality Monitor (iQuam). J. Atmos. Oceanic Technol. 31: 164-180, doi:http://dx.doi.org/10. 1175/JTECH-D-13-00121.1.

Zeng X, Beljaars A. 2005. A prognostic scheme of sea surface skin temperature for modeling and data assimilation. Geophys Res Lett 32(14): L14 605, doi:10.1029/2005GL023030. 